\title{
SHIFTING HOUSEHOLD ENERGY USE IN BANGALORE, INDIA: USING BEHAVIORALLY INFORMED ENERGY REPORTS
}

MINDY HERNANDEZ, KIRAN BHAGAVATULA, SANTHOSH CIBI, RAVICHANDRAN K, SUMATHY KRISHNAN, SUMEDHA MALAVIYA, AND BHARATH JAIRAJ

\section{EXECUTIVE SUMMARY}

\section{Highlights}

- From an equity and economic development perspective, it is critical for more Indian households to become electrified. However, because of the Indian grid's dependence on fossil fuels, household electricity use in India is a major contributor to rising greenhouse gas (GHG) emissions and other externalities, like air pollution.

- Evidence from social science research, largely from the United States, indicates that behaviorally designed household energy reports (HERs) that feature energy savings recommendations and social norm comparisons can decrease inefficient, excess consumption and environmental impacts.

This working paper details the results of a study of over 2,000 households in Bangalore, India, who received HERs in 2018. We find a 7 percent decrease in average monthly energy consumption per household over the course of 12 months, compared to the monthly average consumption of the same households before receiving HERs.

Without a control group of households in Bangalore not receiving HERs, we cannot make a robust causal connection. However, we do find that while per capita energy usage increased by almost 3 percent in the state of Karnataka, in which Bangalore is located, consumption decreased for households in our intervention group over the same time period.

\section{CONTENTS}

Executive Summary ..................................

Introduction ......................................... 5

Study Background and Design ....................... 9

Study Results .................................. 15

Conclusions ........................................ 23

Appendix A .......................................... 24

Appendix B ........................................ 24

Appendix C ....................................... 26

Appendix D .......................................26

Appendix E ...................................... 27

Appendix F.......................................28

Endnotes..........................................29

References ....................................... 30

Acknowledgments................................ 31

Working Papers contain preliminary research, analysis, findings, and recommendations. They are circulated to stimulate timely discussion and critical feedback, and to influence ongoing debate on emerging issues.

Suggested Citation: Hernandez, M., K. Bhagavatula, S. Cibi, R. K, S. Krishnan, S. Malaviya, and B. Jairaj. 2022. "Shifting Household Energy Use in Bangalore, India: Using Behaviorally Informed Energy Reports.” Working Paper. Washington, DC: World Resources Institute. Available online at doi.org/10.46830/ wriwp.20.00046. 
The local utility would have had to increase electricity rates by an estimated 20 percent and wait for at least a year to see a similar 7 percent decrease in energy consumption.

If this scale of energy-saving effect were confirmed, a HER intervention scaled up to the city of Bangalore could save households almost US\$60 million per year and help avoid emissions from the generation of 604 million kilowatt-hours of electricity, compared to the case of normal billing.

\section{Introduction and Context}

India, the second most populous country in the world, has seen steady income growth paired with increased urbanization over the last decade. As more people migrate to urban centers and improve their standard of living, electricity consumption in Indian cities is expected to increase eightfold by 2050 (Shukla et al. 2014). Because of the Indian grid's dependence on fossil fuels, this rise in consumption is a major contributor to increasing GHG emissions. As India's economic growth and urbanization continue to expand, GHG emissions are poised to rise to increasingly deleterious levels. Discovering effective and innovative ways of decoupling rising GDP and energy consumption is important globally and especially urgent in emerging economies like India. Specifically, we need increased efforts and field research on strategies that shift consumption behavior through energy-efficient choices and energy-conservation practices. ${ }^{1}$

The citizen-focused behavior change program called VidyutRakshaka (VR), a joint initiative of Technology Informatics and Design Endeavor (TIDE) and World Resources Institute (WRI) India, is seeking to drive long-term change in energy-use behavior of residential consumers in Bangalore and Chennai through behaviorally designed household energy reports that create more sustainable energy use by tapping into the principles of behavioral science.

\section{About This Working Paper}

Behaviorally informed home energy reports (HERs) have been used for over a decade by electric utility companies in the United States to nudge consumers to change their energy-use behavior. HERs compare a household's energy use to that of its neighbors and include energy conservation recommendations (see Tables ES-1 and ES-2). While research indicates that these HER initiatives help utilities, cities, and consumers decrease household energy use, there has been limited research on HERs in emerging economies. This working paper contributes to closing this research gap.

In Bangalore, TIDE and WRI India have been running VR since $2015 .{ }^{2}$ Launched as a voluntary initiative in partnership with the local electric utility Bangalore Electricity Supply Company (BESCOM), participating households receive customized HERs. As of December 2020, VR covered more than 5,136 households from six different parts of Bangalore. Participants represent a range of households, including homes from one to four bedrooms, homes with one to seven occupants, and energy use ranging from very low (from 50 kilowatt hours [kWh] per month) to very high (from $180 \mathrm{kWh}$ per month). TIDE and WRI India conducted a quasi-experimental study via a pre-post design analyzing the energy use data of over two thousand households in the VR program in order to assess the impact of VR reports on participating households' energy savings. ${ }^{3}$ While this study does not include a control group in Bangalore, we do compare electricity consumption in our study sample to consumption in Karnataka, the state in which Bangalore is located.

VR reports, like most HERs, provide customers with personalized feedback as well as social comparisons and energy-conservation recommendations. Specifically, VR reports provide basic information on current consumption, historical consumption, comparison to neighbors, actionable tips, and energy-savings goals. See Table ES-1 for an excerpt of the VR reports.

In addition to approaching the question of HERs' quantitative impact on energy savings, this working paper uses household surveys and one-on-one interviews to explore the specific aspects of the report that might be driving energy-saving behaviors.

We provide suggestions to improve future versions of VR reports specifically and HERs generally. The findings and recommendations in this working paper are relevant for both electric utilities and policymakers considering how to design scalable behavioral interventions to reduce household energy consumption to sustainable levels without extreme taxation. 


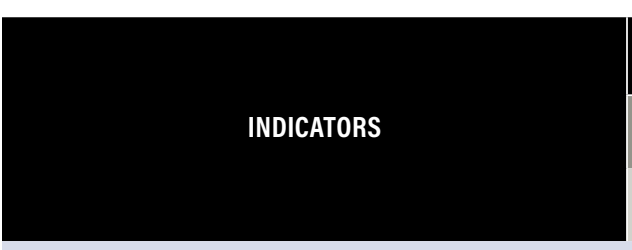

Average monthly consumption in your BHK category in your locality (Units)

Monthly per capita consumption in your BHK category in your locality (Units)

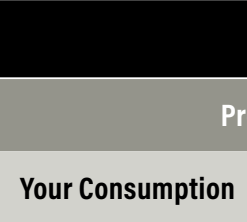

203

18

8
NEIGHBORHOOD COMPARISON

\section{Present Status}

Community Average

259

72
Source: WRI Authors.

Table ES-2 | List of Good Recommendations: Lighting

\section{LIGHTING}

- You can save by shifting CFL to LED lights starting from frequently used rooms. Make use of the Hosa Belakku Scheme of BESCOM.

- Replace your tube light with an energy-efficient light. Start replacing frequently used lights first.

- As there are people staying in your house during the entire daytime, make use of sunlight to reduce usage of lights during the daytime.

\section{The Challenge}

In India, household electricity consumption has more than tripled since 2000, and this rise in household consumption is a major contributor to the nation's rising GHG emissions. ${ }^{4}$ As India becomes increasingly urbanized and household incomes continue to increase, emissions will rise. Indeed, India is predicted to experience the fastest growth rate of any nation in the energy consumption of buildings, and this rise is due to electricity consumption specifically (Capuano 2020).

Even with these recent increases, India's per capita electricity consumption is still approximately 30 percent lower than the global average. Millions still lack access to reliable electricity in rural areas, posing a significant barrier to economic and human development (IEA 2021). Therefore, we must find ways to decouple economic growth and its corresponding increases in quality of life from the emission of global and local pollutants. Designing and testing models that demonstrably decrease household energy consumption and increase the use of energy-efficient behaviors is especially critical in emerging economies like India.

\section{Key Findings}

\section{We find evidence of a significant 7 percent decrease in average monthly energy consumption per household from pre to post VR participation} (2015 to 2019), which translates to a cost savings of INR 54 per household per month. While these savings may seem modest at the individual household level, projected at scale to Bangalore this would translate to a savings of almost $\$ 60$ million per year and over 604 million kilowatt-hours of electricity saved compared to the case of normal billing. (See Appendix A for calculations.) Without a control group of households in Bangalore not receiving HERs, we cannot make a robust causal connection. However, we do find that while per capita energy usage increased by almost 3 percent in the state of Karnataka, in which Bangalore is located, consumption decreased for households in our intervention group over the same period.
High-energy users brought their electricity consumption down while low-energy users' consumption increased. Mirroring prior studies on HER reports, we find that households that were low- 
energy users (defined as households with below average monthly energy consumption) before receiving VR reports increased their energy consumption by 6.3 percent while households that were high-energy users (defined as households with above the average monthly energy use) before receiving VR reports decreased their energy consumption by 11.6 percent.

We find suggestive evidence that the specific goals and energy-saving recommendations may be driving energy-saving behaviors more than the social comparisons. VR reports contain a comparison of electricity consumption with neighbors (social norm comparison), a comparison to the household's historical consumption pattern, and actionable feedback in the form of an energy-savings goal for the household and customized recommendations to save energy. In our qualitative analysis and survey data we find that 75 percent of participating households report that the social norm comparison section of the VR report was unclear or only somewhat clear. When asked explicitly if there were any sections of the report that they ignored in their decision-making, all of the interview respondents reported ignoring this neighborhood comparison section.

In contrast, a vast majority of survey respondents reported that the sections titled "Goals for You" and "Recommendations" were both clear and motivating, and all interview respondents reported that the recommendations section was the most useful. The "Goals for You" section lays out a potential energy-savings goal for the household in terms of kWh and in terms of the tariff rate associated with the household's energy goal. The recommendations section is customized to each household based on an initial baseline survey and provides actionable suggestions like switching to LED lights. As one participant pointedly noted, "The recommendation section is clear, but other sections don't make sense."

\section{We find suggestive evidence that the VR reports may have changed the way VR recipients pur-} chased appliances. Prior research from the United States (Allcott and Rogers 2014) suggested that HERs may increase households' capital stock, which includes both physical stock like energy efficient appliances and LED lights as well as consumption capital, which can be thought of as a stock of energy-use habits like turning off fans when not in use. Similarly, we find that the only aspect of the VR report that is significantly correlated with energy saving is respondents' confirming that they fol- lowed the recommendations section of the VR report while purchasing appliances. The subsample of households who participated in the follow-up survey is relatively small (n $=118$ out of 2,196 participants), but the patterns found are consistent with both the administrative and focusgroup findings.

While our administrative data sample is relatively large (n $=2,196$ ), we did not use a randomized control treatment design, nor were we able to obtain individual or aggregate data for households without HERs; therefore, causality testing on the effects of the reports themselves in Bangalore is limited. This research is intended to be hypothesis suggesting. As noted below, additional counterfactual analyses, with or without randomized control studies, are needed to test fully the hypothesis.

\section{Recommendations}

Drawing on the findings from the quantitative and qualitative data of the HERs applied in Bangalore, we suggest the following possible improvements to the VR reports specifically, as well as to HERs generally:

Test and Scale: HERs have the potential to deliver energy and cost savings to households with corresponding benefits for the environment and should be considered for expansion at the state and national level. Scaling efforts should be deployed using a continuous learning approach to ensure improvements in the design and delivery of HERs. Specifically, randomized control trials can tease out the underlying mechanisms driving savings behaviors. Additionally, because local contexts differ, it is critical to conduct research on HERs' impact on energy savings in different cities, regions, and countries.

Simplify and Clarify: Providers of HERs should consider designing reports that consist only of clear information on current energy usage and costs; comparison with neighbors via one simple, culturally appropriate icon or message; and a goals and recommendations section. Sections that remain in a slimmed-down HER should be made as clear and easy to understand as possible by using familiar mental models (happy/sad face or other culturally relevant icons), clear language, and visual cues.

Leverage the Recommendations Section: All interview respondents reported that the recommendations section is easiest to follow or understand while survey respondents indicated that the recommendations section was the most 
motivating. Efforts should be spent prioritizing these recommendations and making them as clear and actionable as possible.

Focus on High-Energy Users: Our study indicates that specific subgroups like households who consume more energy than comparable local households are most likely to benefit from HERs. Therefore, focusing on these consumers can stretch limited dollars. If utility companies or organizations face limitations on implementation, prioritizing enrolling highenergy households may be a way to maximize the program's impact.

\section{INTRODUCTION}

\section{Rising GDP, Rising Emissions}

Even considering global contractions in the wake of the COVID-19 pandemic, India is projected to be the fastest growing economy in the world in 2021 and 2022 (IMF 2021). This is good news as historically, rising GDP is associated with positive impacts on human development in the form of improved health and education (Conceição 2019). The challenge is that as countries advance on the human development index, research indicates their ecological footprint per person rises as well (Cumming and von Cramon-Taubadel 2018). See Figure 1.

\section{Household Energy Consumption Rises}

India, the second most populous country in the world, has seen steady income growth paired with increased urbanization over the last decade (OECD 2019). As the economy grows and more people move into electrified cities, people gain access to products and services that make their lives more comfortable: air conditioners, fans, and warm showers.

In India's residential energy use sector specifically, household consumption has more than tripled since 2000 (Chunekar and Mulay 2017). This rise in consumption is a major contributor to rising GHG emissions (Myhrvold and Caldera 2012). Drawing on household microdata from India's 60 largest cities, including Bangalore (the focus of

Figure 1 | Per Capita Ecological Footprints Increase with Human Development

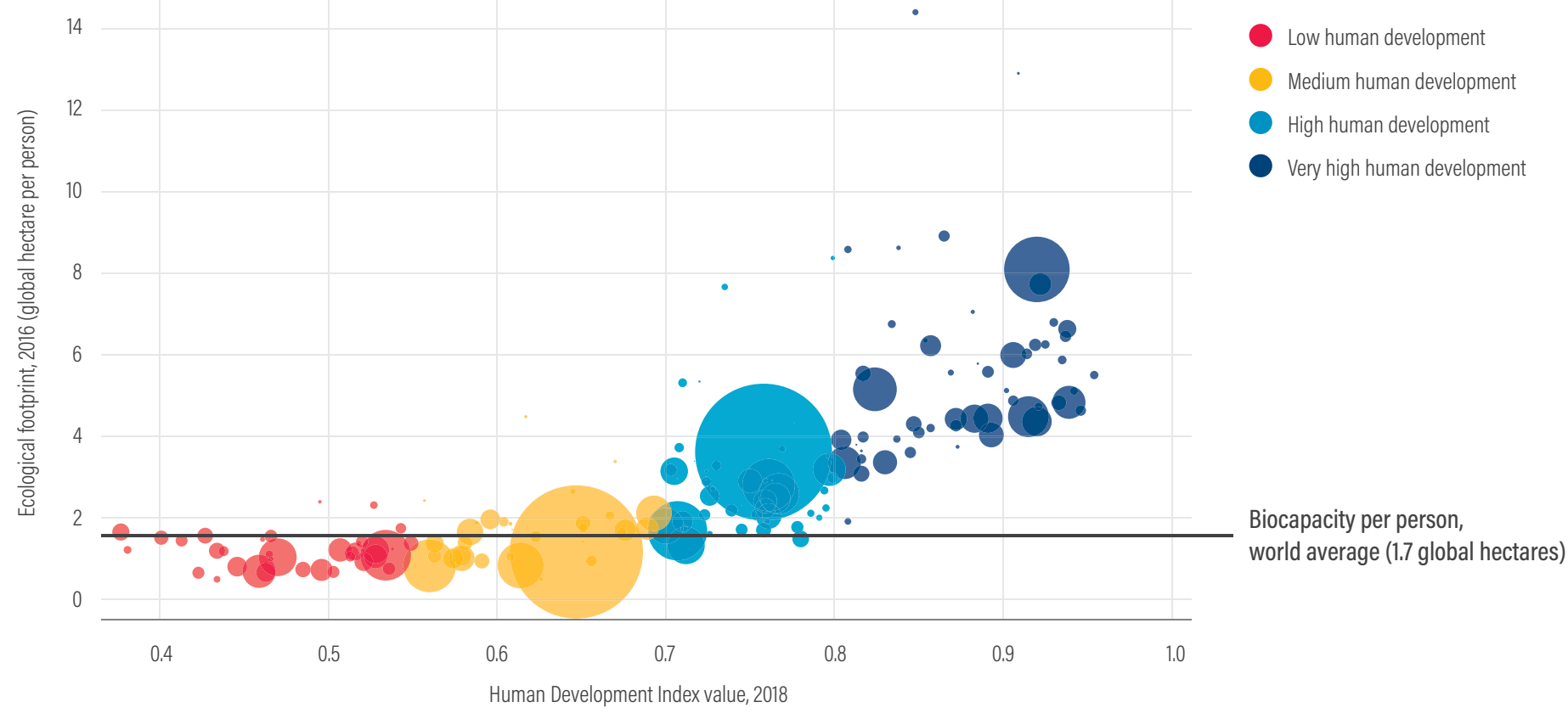

Note: Data cover 175 countries in the Global Ecological Footprint Network database (www.footprintnetwork.org/resources/data/; accessed 17 July 2018 ). As used here, the ecological footprint is a per capita measure of how much area of biologically productive land and water a country requires, domestically and abroad, to produce all the resources it consumes and to absorb the waste it generates. Each bubble represents a country, and the size of the bubble is proportional to the country's population.

Source: Original Data from Cumming and von Cramon-Taubadel (2018), reproduced by Conceição (2019). 
this working paper), researchers mapped household GHG emissions patterns and their determinants and found that increases in household income and access to electricity are driving residential emissions growth (Ahmad et al. 2015). ${ }^{5}$ As India becomes even more urban and household incomes continue to increase, GHG emissions are poised to rise to increasingly deleterious levels. Indeed, India is predicted to experience the fastest growth rate of any nation in energy consumption by buildings specifically due to electricity use from 2018 to 2050 (Hojjati 2019).

\section{India's Energy Consumption in Context}

India's rising energy consumption is juxtaposed against two realities: First, India's per capita electricity consumption was $873 \mathrm{kWh}$ in 2018-19 (MOSPI 2020), which was three and a half times lower than the global average in 2018 (IEA 2021). Secondly, significant village electrification has been achieved, but recent surveys indicate that at the household level, both availability and the quality of supply are still major challenges: Although 92 percent of households report having access to electricity, this electricity is only available for 70 percent of the day on average (Bali et al. 2020). The lack of consistent access to lights, computers, and phone charging poses significant barriers to a household's economic and educational advancement. More Indian households should have access to consistent electricity, but managing load growth is a challenge.

\section{The Promise and Urgency of Demand-Side Interventions in India}

To manage increasing energy consumption, Indian power utilities have predominantly relied on supply-side improvements, such as upgrading distribution infrastructure or buying more power, and have paid less attention to demand-side measures. One well-studied demand-side intervention is the behaviorally informed HER. These HERs engage consumers by providing personalized feedback on energy use, comparative feedback or social norm messages on energy use (this is information that compares a household's consumption with similar households), and energy-conservation recommendations.

While evidence from the United States on demand-side HERs has been consistently promising, research in the Indian context is limited, although positive. ${ }^{6}$ Specifically, a randomized control trial of the impact of HERs in New Delhi, India (Sudarshan 2017) found 7 percent less energy consumption among households receiving HERs, compared to households who did not receive HERs. A 2019
HER program covering 200,000 residential consumers in southern and western Delhi was launched by Delhi-based utility BSES Rajdhani Power Limited, in partnership with Oracle Utilities with funding from the U.S. Trade and Development Agency. However, impact data from that study are not yet publicly available.

Looking beyond impact data, there is an open question as to which features (including personalized feedback, comparative feedback, and energy-saving tips) drive the success of HERs and how reports can be designed as effectively as possible. The goal of this working paper is therefore to provide an estimate of the effect of HERs on energy consumption in the Indian context and provide actionable suggestions on improving the features of HERs to make them as effective as possible.

Since 2015, TIDE, a local NGO, WRI India, and the electric utility BESCOM have been designing and testing one such intervention: the consumer-focused HER program known as VidyutRakshaka (VR). VR was piloted in the city of Bangalore where residential electricity consumption has been growing faster than in the commercial and industrial sectors (KERC 2019). Interested consumers signed up to participate between 2016 and 2018 and received HER reports within three months of signing up, with social comparisons and customized recommendations to save energy.

\section{Traditional Approaches and the Role and Promise of Applied Behavioral Economics}

Attempts to decrease household energy use are traditionally informed by neoclassical rational actor models and often involve information-based interventions, like labeling appliances as energy-efficient (Rivas et al. 2016), adjusting energy pricing, as in peak-load pricing (Munasinghe 1981), and offering financial incentives, like subsidizing energy-efficient household appliances or solar power. Because the neoclassical model assumes rationality and full information, these strategies often assume that people will be aware of pricing differences, will attune to new information, and will correct overconsumption accordingly.

Traditional interventions have limitations. There is evidence that taxes on consumption must be relatively high to change behavior; some research indicates that achieving a 2 percent reduction in household energy use requires raising energy prices by 11 to 20 percent, making them expensive for consumers and subject to public pushback (Allcott 2011). These taxes are often regressive 
as they affect low-income consumers relatively more than higher-income consumers. Smaller price shifts might be more palatable but are likely to be ineffective because many individuals fail to notice such small tax increases. (Chetty et al. 2009). Interventions that focus on information alone have limitations as consumers may fail to notice new information or may not be able to process complex information (Marois and Ivanoff 2005); and there is evidence that, despite our best intentions, information does not always translate into action (Sheeran 2003).

Regulations like efficiency standards on appliances and residential construction codes that mandate minimum levels of building efficiency can also be effective policy tools. However, regulations may not always be politically feasible. And even when feasible and implemented, human behavior continues to play a critical role as people determine how much energy to consume, even if that consumption is through an energy-efficient appliance or within an energy-efficient building.

\section{Applying Behavioral Economics to Household Energy Consumption}

Bounded rationality (Simon 1957; Klaes and Sent 2005) offers a different perspective and posits that while humans act rationally, our rationality is bounded by a number of factors and biases. Two relevant biases in the energyconsumption context include the empirical insight that human behavior is often reference-dependent and particularly influenced by social norms. Additionally, there is evidence that making information actionable and accessible can spur behavior change across a number of domains.

\section{REFERENCE POINTS}

People depend on reference points to evaluate their current and future behaviors. See Kahneman and Tversky (1979) for more on reference-dependent preference and nonlinear probability weighting and Nolan et al. (2008) and Schultz et al. (2007) for social comparisons as reference points.

For example, in the context of energy consumption, if an energy bill informs a household that it has used 200 $\mathrm{kWh}$ of energy in January, there is no reference point to help people determine whether $200 \mathrm{kWh}$ is too much energy, too little, or just right. As discussed in more detail below, providing people with direct feedback on their behavior, coupled with a social norm as a reference point, has been shown to shift behavior in prosocial, pro-environmental ways.

\section{SOCIAL NORMS}

Social norms ${ }^{7}$ can be defined as cultural phenomena that prescribe and proscribe behavior in specific circumstances (Hechter and Opp 2001). We internalize how others behave from the time we are children, but sometimes others' behavior is unobservable or underestimated. Social science literature has shown that making peers' behavior observable by providing people with information on how their behavior compares to others in their social group (social norm comparisons or comparative feedback) can affect behavior in a number of pro-social domains, including voting, decreasing littering, and-critically-energy conservation (Allcott and Mullainathan 2010; Cialdini et al. 1990; Gerber and Rogers 2009; Goldstein et al. 2008).

\section{ACTIONABLE FEEDBACK (RECOMMENDATIONS, ENERGY-SAVING TIPS)}

In addition to reference points and social comparisons, providing households with actionable information on how to save energy is a common feature of HERs. Norm activation theory posits that behavior change is most likely when people are both aware of an issue (e.g., my energy consumption is higher than my neighbors) and believe that they can influence that behavior (Fischer 2008; Schwartz 1977). In this latter domain, providing accessible tips on how to change behavior can lower the perceived cost of action by making behavior change easier and therefore more likely.

\section{HISTORICAL USE OF BEHAVIORAL INSIGHTS IN ENERGY CONSERVATION}

Efforts to conserve energy by leveraging behavioral insights date back to at least the mid-1970s. (Delmas et al. 2013) While using social norms or peer comparisons in these energy conservation efforts is a well-known behavioral strategy, it is not the only one that has been tested. A 2013 meta-analysis by Delmas et al. found that the key information-based strategies used in HER-like experiments included providing individualized feedback, energy-savings tips, energy audits, monetary incentives, and, as mentioned, social or peer comparisons. The impact of these strategies has been largely positive. Across these strategies, individuals in the experiments reduced their electricity consumption by an average of 7.4 percent (Delmas et al. 2013).

Behavioral interventions aimed at energy conservation have been replicated multiple times across geographies (although the vast majority of experiments have been in the global North). A selection of four well-known and relevant studies are summarized in Table 1 . Key features of the interventions include providing direct feedback on 
energy use, social norm messages, and energy-saving tips. Average energy savings from the interventions noted here range from 2 to 9 percent.

\section{The Boomerang Effect}

While descriptive social norm messaging has been shown to bring energy use down, there is some evidence that giving lower-than-average consuming households information that their consumption is below the norm can cause a boomerang effect wherein low-consuming households bring their consumption up to meet the norm. ${ }^{8}$ (Allcott, 2011; Allcott and Rogers 2014; Schultz et al. 2007). As discussed in detail in Section 1.4 (See Figure 10), this dynamic could be playing a role in the HER program in Bangalore, as we found that below-average consumption households increased their consumption by 6 percent while high-consuming households decreased their energy usage by 12 percent.

\section{Opportunities for Scale}

While the energy savings detailed earlier may seem small at an individual level (with household reductions averaging 2-9 percent), when scaled citywide, statewide, or nationally, small individual energy-conservation actions lead to large impacts and long-term changes in behavior. The behaviorally designed energy reports that feature direct feedback and social norm comparisons from the company Opower (now Oracle) have helped utility partners save over 11 terawatt-hours (TWh), the equivalent of more than $\$ 1.1$ billion in consumer savings and an abatement of more than 5 million metric tons (12 billion pounds) of carbon emissions (Opower 2016).

Given the promising evidence and rising household energy use and corresponding increases in emissions, WRI India and its partner TIDE have been interested in applying behavioral science to household energy reports since 2015 when both organizations launched an effort to evaluate their behaviorally designed energy reports in Bangalore, India.

Table 1 | Selected Studies on Behavioral Mlessaging to Promote Energy Saving

\begin{tabular}{|c|c|c|c|c|}
\hline YEAR & LOCATION & INTERVENTION FEATURES & FINDINGS & AUTHORS \\
\hline 2007 & $\begin{array}{l}\text { San Marcos, } \\
\text { California }\end{array}$ & $\begin{array}{l}\text { Messages were sent to a group of homes } \\
\text { with social comparisons and energy-saving } \\
\text { tips; a second set of messages was sent with } \\
\text { social comparisons and injunctive norms. See } \\
\text { boomerang effect, below, for more details. }\end{array}$ & $\begin{array}{l}\text { Social comparison messages and energy-saving tips } \\
\text { produced energy savings among previously high- } \\
\text { consuming households and a slight increase in energy } \\
\text { use among previously low-consuming households. Use } \\
\text { of injunctive norms (a happy or sad face) neutralized the } \\
\text { boomerang effect. See below, for more details. }\end{array}$ & $\begin{array}{l}\text { Schultz } \\
\text { et al. } 2007\end{array}$ \\
\hline $\begin{array}{l}2011- \\
2014\end{array}$ & Multiple sites, U.S. & $\begin{array}{l}\text { HERs were sent with social comparisons and } \\
\text { energy-saving tips }\end{array}$ & $\begin{array}{l}\text { Households receiving the reports reduced electricity } \\
\text { consumption by an average of } 2 \% \text { across } 17 \text { experiments, } \\
\text { Researchers estimate that achieving similar reductions } \\
\text { by price increases would have meant increasing energy } \\
\text { prices by } 11 \text { to } 20 \%\end{array}$ & $\begin{array}{l}\text { Opower 2016; } \\
\text { Allcott and } \\
\text { Rogers } 2014\end{array}$ \\
\hline 2013 & $\begin{array}{l}\text { Multiple sites } \\
\text { across the U.K. }\end{array}$ & $\begin{array}{l}\text { Messages sent to some households with } \\
\text { social comparisons messages only. A second } \\
\text { treatment group received social comparisons } \\
\text { and energy saving tips }\end{array}$ & $\begin{array}{l}\text { The average treatment effect for households receiving } \\
\text { norms only messages is } 2.9 \% \text { while the treatment effect } \\
\text { for those receiving norms with information is } 9.6 \% \text {. }\end{array}$ & $\begin{array}{l}\text { Dolan and } \\
\text { Metcalfe } 2012\end{array}$ \\
\hline 2017 & New Delhi, India & $\begin{array}{l}\text { Provided social comparisons and energy- } \\
\text { saving tips }\end{array}$ & $\begin{array}{l}\text { Households provided peer comparisons and generic } \\
\text { energy-saving tips reduced summer season consumption } \\
\text { by } 7 \% \text {. Sudarshan found the impact of the intervention } \\
\text { equivalent to increasing tariffs by about } 12.5 \% \text {. }\end{array}$ & $\begin{array}{l}\text { Sudarshan } \\
2017\end{array}$ \\
\hline
\end{tabular}

Notes: ${ }^{a}$ There were eight experiments on the West Coast, four in the rural Midwest, two in the urban Midwest, two in the suburban mountain region, and one in the urban Northeast. ${ }^{b}$ The study included multiple treatment arms and levels of analysis; here we focus on the treatments and results most relevant to our research. 
STUDY BACKGROUND AND DESIGN

\section{Technology Informatics Design Endeavor (TIDE) and VidyutRakshaka}

TIDE was established over 26 years ago in India, with the goal of promoting sustainable development through innovative technological interventions. Since inception, TIDE has developed, adapted, and transferred technology options like improved cook stoves, biogas, biomass gasification, biomass briquetting, and energy audits. A key focus in TIDE's work on electricity has been the design and implementation of VR, a demand-side management program for residential electricity consumers that applies behavioral science insights into energy reports designed to increase energy conservation.

There are two main elements of the VR program:

1. Widespread Registration: TIDE works with VR stewards' who are trained to conduct outreach and registration drives in geographic areas throughout Bangalore. TIDE also promotes VR through apartment owners' associations, resident welfare associations, and other citizen platforms (posters or flyers and e-mails). To expand outreach further, TIDE launched an Android and smartphone registration application in 2018 to target smartphone users. Registration for the VR program is free for households.

2. Data Analysis for Personalized Energy Reports: For each household registered, TIDE obtains electricity bills from the utility BESCOM for the three years prior to VR sign-up. This administrative utility's data are added to the demographic data to create a profile for each household. VR stewards visit these households to collect additional household data on energyconsuming appliances or equipment and demographic information on the household (number of bedrooms and number of occupants). Data are aggregated and analyzed by household size (defined by number of occupants in a household); house size, as determined by bedrooms, hall, and kitchen (BHK), defined by number of bedrooms: 1BR, 2BR, 3BR and 4+ BR); geographic area (by pincode ${ }^{10}$ ); and energy use over time. (See Appendix B for details on the household data collected for this study.)

The aggregated analysis is used to create a HER (referred to as the VR report) specifically targeted to each household that provides information on two main aspects:
Relevant reference points and comparisons. The report compares the household's energy use against its enrolled neighbors (using the geographic area model and comparing similar household sizes), against its historical consumption for the same time period (using the historical consumption model), and against an optimal user (using the optimal use model). ${ }^{11}$

Actionable feedback. The household is given an energy-saving goal and detailed recommendations to achieve that goal.

Each aspect is laid out in a section of the VR report. Details and illustrative examples of each section are below.

\section{Relevant Reference Points and Comparisons (2 Sections)}

\section{My Consumption and Neighborhood Comparison}

This section provides VR customers with their energy use per $\mathrm{kWh}$ per month ${ }^{12}$ and then translates this use into a reference point by classifying the customer as an Energy Saver (if household energy consumption is below the geographic area average), Champion (if household consumption is at the geographic area average), or Future Champion (if household energy consumption is above the geographic area average). See Table 2 for a sample of this section. ${ }^{13}$ Homes with similar numbers of BHKs are considered together.

\section{Table 2 | My Consumption}

\section{SUMMARY}

You are presently a VidyutRakshaka Energy Saver

Consuming 203 average units per month in a 4 BHK or larger category in Bangalore Urban, Bangalore - 560043

You were classified as a VidyutRakshaka Future Champion in your first assessment (Feb - 2017)

Consuming 223 average units per month in a 4 BHK in Jalavayuvihar S.0, Bangalore - 560043

\section{Categories:}

- Energy Saver - Consuming below neighbourhood average

- Champion - Consuming neighbourhood average

- Future Champion - Consuming above neighbourhood average 
This section also compares customers to their neighbors over time.

2. Historical Comparison: The Household's Use over Time

Using the electricity billing data of the last three years for each household, this section compares customers to their own energy use over time and assigns each household a category to demonstrate use over time.

\section{Actionable Feedback (2 Sections)}

1. Optimal Use Assessment and Specific Recommendations

This section details how the VR household's consumption compares to optimal consumption on specific energy use areas like lighting and heating and then provides a binary yes/no demarcation indicating whether the home's consumption is below or above optimal. ${ }^{14}$

This section also includes a list of actionable recommendations that the customer can take in each category where the customers' energy use is inefficient. These are specific to the household based on the ownership and usage of appliances and information shared through the registration questionnaire. An example of specific suggestions follows:

\section{Goals for You (Financial Savings)}

In India, electricity rates are based on the consumption slab (or tax category or bracket), which increases as consumption increases. This final section informs the household of the decrease in $\mathrm{kWh}$ needed to move to the next lower consumption slab and thereby decrease energy costs. For example, under the existing

\section{Table 3 | Neighborhood Comparison}

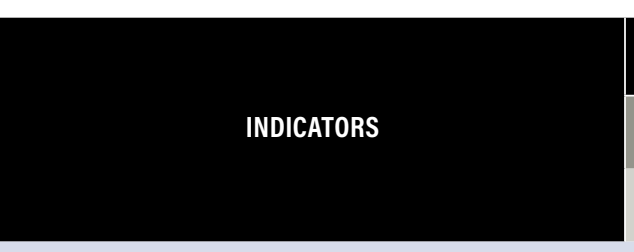

Average monthly consumption in your BHK category in your locality (Units)

Monthly per capita consumption in your BHK category in your locality (Units)

Source: WRI Authors.
NEIGHBORHOOD COMPARISON

\begin{tabular}{|c|c|c|c|}
\hline \multicolumn{3}{|c|}{ NEIGHBORHOOD COMPARISON } \\
\hline \multicolumn{2}{|c|}{ Present Status } & \multicolumn{2}{c|}{ First Assessment Status } \\
\hline Your Consumption & Community Average & Your Consumption & Community Average \\
203 & 259 & 223 & 142.8 \\
\hline 18 & 72 & 20 & 22 \\
\hline
\end{tabular}

\section{Table 4 | Household Use over Time}

Spender to saver A household that has increased consumption by at least $5 \%$ year-on-year for 3 years before joining the program but has decreased its spending by more than $5 \%$ after 1 year of joining VR program

Consistent saver A household that has reduced consumption by at least $5 \%$ year-on-year for 3 years before joining the program and continues to reduce at the same rate or better after 1 year of joining VR program

Saver to spender A household that has reduced consumption by at least $5 \%$ year-on-year for 3 years before joining the program but has increased its spending by more than $5 \%$ after 1 year of joining VR program

Consistent A household that has increased consumption by more than $5 \%$ year-on-year for 3 years before joining the program and continues to spender increase at the same rate or higher after 1 year of joining VR program

Inconsistent A household whose consumption has varied by more than $5 \%$ year-on-year without a clear trend (increase in second year followed by a decrease in third year or decrease in second year followed by increase in third ) in the 3-year period before joining the program 


\section{YOU ARE AN INCONSISTENT USER}

Your annual electricity consumption is fluctuating. Follow our recommendations to save electricity.

Spender to Saver - You are moving towards decreasing consumption

Consistent Saver - You are steadily decreasing consumption

Saver to Spender - You are moving towards increasing consumption

总 Consistent Spender - You are steadily increasing consumption

Inconsistent - Your consumption behaviour is erratic

User with Partial Data - Your available data is not enough for a complete analysis

Source: WRI Authors.

Table 6 | Category-wise Recommendations

YOUR AVERAGE MONTHLY ELECTRICITY CONSUMPTION BASED ON OPTIMAL MODEL FOR A SIMILAR HOUSEHOLD IN A CITY LIKE BANGALORE

\begin{tabular}{|c|c|c|c|c|}
\hline Indicators & $\begin{array}{l}\text { Your Present Monthly } \\
\text { Consumption (Units) }\end{array}$ & $\begin{array}{l}\text { Optimal Monthly } \\
\text { Consumption (Units) }\end{array}$ & $\begin{array}{l}\text { Is Your Consumption Higher } \\
\text { Than Optimal? }\end{array}$ & $\begin{array}{l}\text { Your Monthly Consumption } \\
\text { in First Assessment (Units) }\end{array}$ \\
\hline Lighting & 11 & 35 & NO & 3 \\
\hline Heating & 0 & 31 & NO & 0 \\
\hline Cooling & 67 & 89 & NO & 17 \\
\hline Appliance & 45 & 160 & NO & 29 \\
\hline Entertainment & 2 & 20 & NO & 26 \\
\hline
\end{tabular}

Source: WRI Authors

\section{Table 7 | List of Recommendations}

\section{SPECIFIC RECOMMENDATION EXAMPLE: LIGHTING}

You can save by shifting CFL to LED lights starting from frequently used rooms. Make use of the Hosa Belakku Scheme of BESCOM.

Replace your tube light with an energy-efficient light. Start replacing frequently used lights first.

As there are people staying in your house during the entire daytime, make use of sunlight to reduce usage of lights during the daytime.

Source: WRI Authors. 
tariffs in Bangalore, a household consuming $220 \mathrm{kWh}$ units per month will face tariffs that are 15 percent higher than a household in the next consumption slab, which is at 200 units. Therefore, if this illustrative household consumed just 20 units less, it would save money by moving to the next lower tariff slab.

\section{Study Overview and Research Questions}

This working paper contributes to existing research by quantifying the impacts of VR's home energy reports on energy savings in an emerging country context, Bangalore India. In addition, because there is limited research on the underlying mechanisms driving energy savings behavior, we also explore specific aspects of the VR report that might be influencing (or not) energy savings behaviors. ${ }^{15}$ The study aimed to answer three broad research questions:

1. What is the effect of VR reports on energy savings (as measured by average monthly kWh usage per household) among VR customers?

2. What aspects of the VR report might be driving energy-saving behaviors?

3. How can future VR reports be improved?

Specific sub-questions, methods, and notes on data cleaning are detailed in Appendix C.

\section{Methods}

\section{Study Design and Sample Selection}

We use a mixed-methods design. To capture the effect of VR reports quantitatively, we use administrative energy reports data from BESCOM to conduct a pre-post analysis of average monthly household energy use before signing up for VR and after receiving VR reports for one year. A study sample of 2,196 households was selected using a stratified sampling method to ensure that key subgroups (including pincodes, house size, occupancy size) were representative of the full VR sample. Households were then randomly selected within each strata. See Appendix B for more details on the sample.

To understand the relationship between the specific aspects of the VR report and household savings behaviors (See research questions 2.1-2.3), we surveyed (via oneon-one phone surveys) a subsample of 120 of the 2,196 households. (See Appendix D for survey.) This subsample was also selected using a stratified sampling method to ensure that key subgroups were representative of the full

\section{Table 8 | Goal Setting}

The difference between average monthly consumption and the last tariff slab is 3.0 units.

Please set your Saving goal based on the customised recommendations under the "Category-wise Recommendations."

Please download the VR app to access the "Generate Savings" feature and other resources.

Source: WRI Authors.

study sample (at approximately 10 percent of the total sample for each subgroup). Households were then randomly selected within each strata.

Survey and energy-use data were then merged (scrubbing all personally identifiable information and using unique identifiers to match survey respondents to their energyuse data) to explore the relationship between participants' views of the VR report (via survey, self-reported) and household energy use. For additional qualitative insight, we conducted one-on-one phone interviews (n =6) to further explore how families use, perceive, and are motivated by the report. ${ }^{16} \mathrm{We}$ also asked what these participants would like to see on their VR reports in the future. See Appendix $\mathrm{C}$ for a detailed description of the study's methods.

We compare households' monthly energy usage (in kWh) for 36 months before signing up for VR (pre-VR energy use) to the average monthly energy use of the same households for 12 months after receiving at least one VR report. These are not the same months, as people signed up at different times. Additional analysis disaggregating energyuse data by household characteristics (occupancy, BHK, pincode, pre-VR energy use) is also reported.

The administrative data and survey results capture behavior pre-COVID-19. The one-on-one interviews were conducted between August 7 and 19, 2020, after the COVID pandemic to capture additional insights and realities that households faced after living under lockdown in India.

\section{Considering Counterfactuals}

This study uses a pre-post design and compares the VR study sample before participants received VR reports to the same sample after receiving the reports. We do not have a control group to supply a robust counterfactual. To understand the energy use of our study sample 
over time, we consider three possible counterfactuals that might reasonably explain a change in household energy consumption:

1. Residential tariffs: whether the cost of energy changed over the study period.

2. Weather changes: whether the weather changed significantly over the study period in ways that might indicate the need for more or less energy use (e.g., increased fan use over hotter years).

3. Changes in energy use in Karnataka and India: For further context, we compare energy use between our study sample in Bangalore, India, to per capita energy use over the same period in Karnataka, India, the state in which Bangalore is located. ${ }^{17}$

\section{RESIDENTIAL TARIFFS}

Figure 2 describes the average tariffs for residential consumers in Bangalore for the period April 2015 to March 2020, in nominal terms. Adjusting for inflation, there was a yearly real increase in tariffs, both during the pre-VR period (July 2015 to June 2018) as well as the post-VR period (August 2018 to July 2019). The average tariff from the pre-VR period was 4.88 INR per unit, ${ }^{18}$ while the post-VR period had a tariff of approximately 5.42 INR per unit (in 2015 terms). At an all-India level, electricity demand ( $\mathrm{kW}$ ) for residential consumers is price inelastic (CEA 2019), meaning that an increase in electricity prices doesn't result in a proportional decrease in electricity demand.

The slight tariff increase could be a contributing factor in electricity reduction among our study sample, although general usage trends, which increased during this period (and are discussed below), suggest otherwise.

\section{WEATHER}

Figure 3 summarizes monthly average temperatures in Bangalore for the study period, extracted from the India Meteorological Department (IMD). The temperatures in the 12 months following the introduction of VR reports were highly comparable to the minimum and maximum temperatures observed in the three years preceding the intervention. The months following the intervention were on average as warm as or warmer than the same months in the previous three years.

Despite these slight variations in weather, there is no statistically significant difference between the monthly temperatures from before (2015-2018) and after (20182019) the introduction of VR reports.

Not surprisingly, given the nonsignificant variations in weather, we find that the temporal relationship between average temperatures and electricity consumption is weak (Figure 4).

Figure 2 | Average BESCOM Tariffs for Residential Consumers 2015-2020 (Nominal Values)

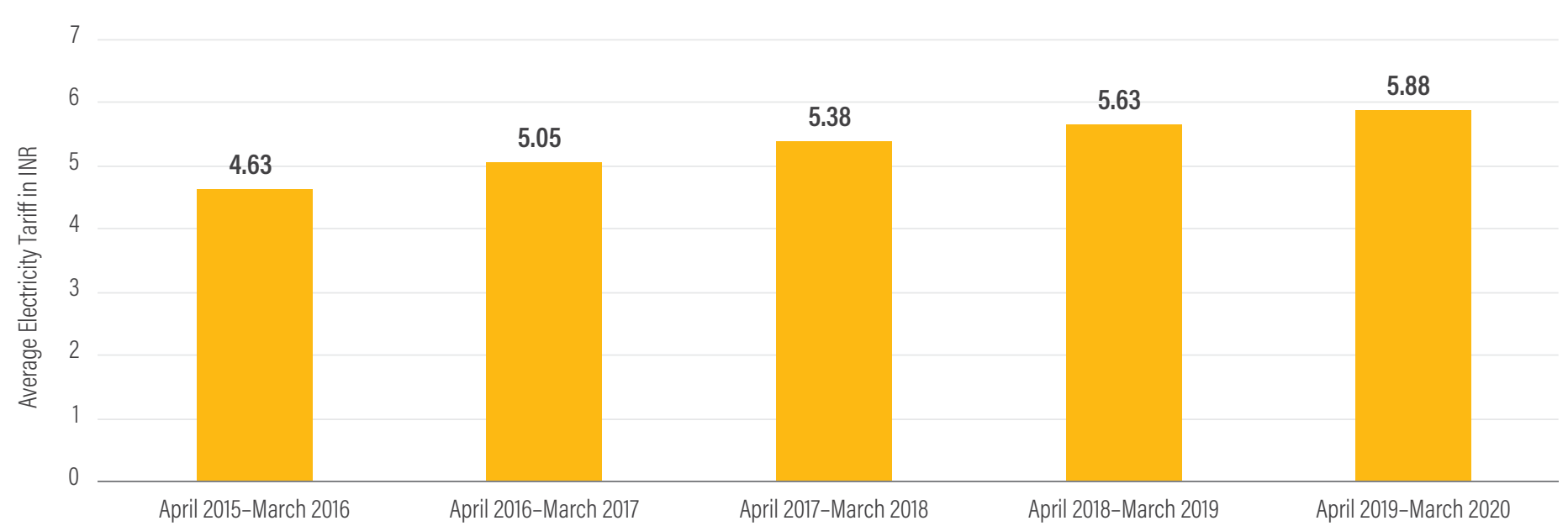

Note: Accessed from https://karunadu.karnataka.gov.in/kerc/Pages/Tariff-Orders.aspx.

Source: WRI Authors using data presented by BESCOM in tariff orders. 
Figure 3 | Average Monthly Temperature in Bangalore, India 2015-2019

40

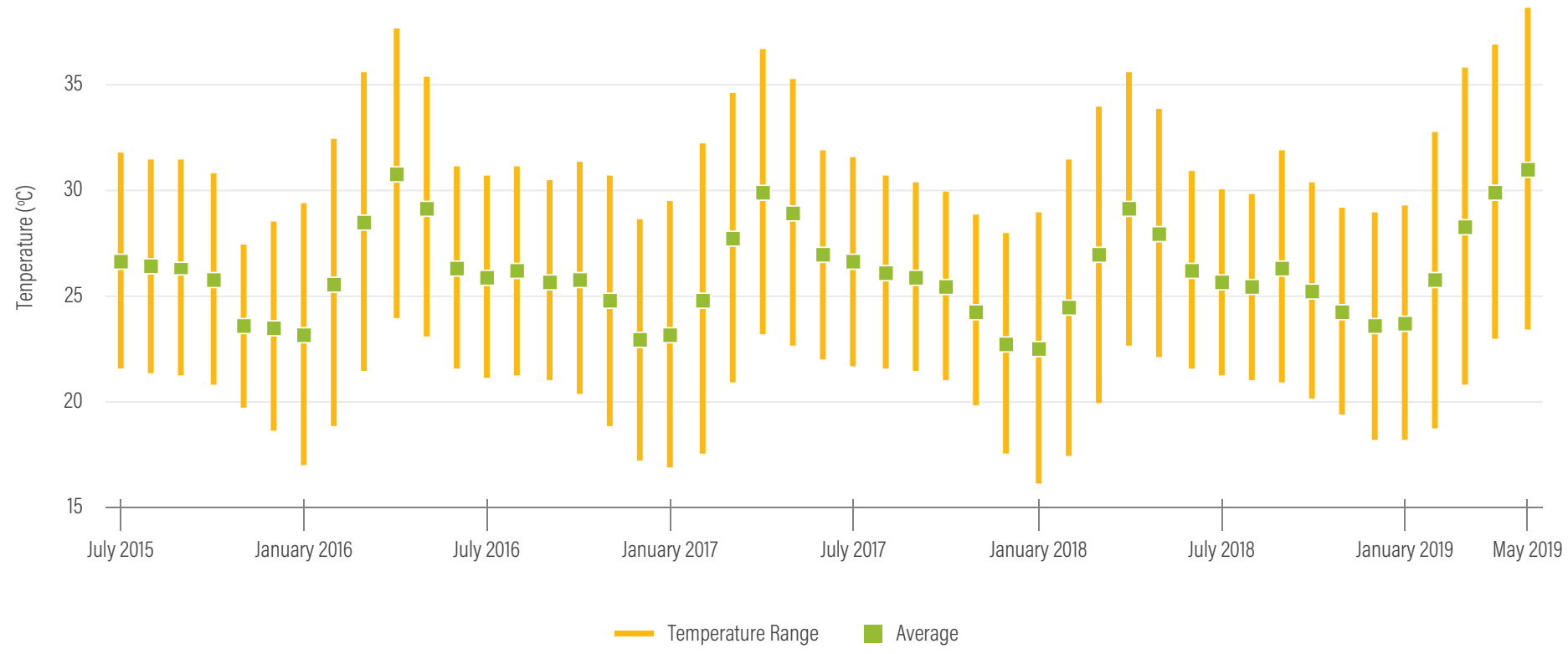

Source: WRI Authors; extracted from the India Meteorological Department.

Figure 4 | Average Monthly Temperature and Household Electricity Consumption in Bangalore, 2015-2019

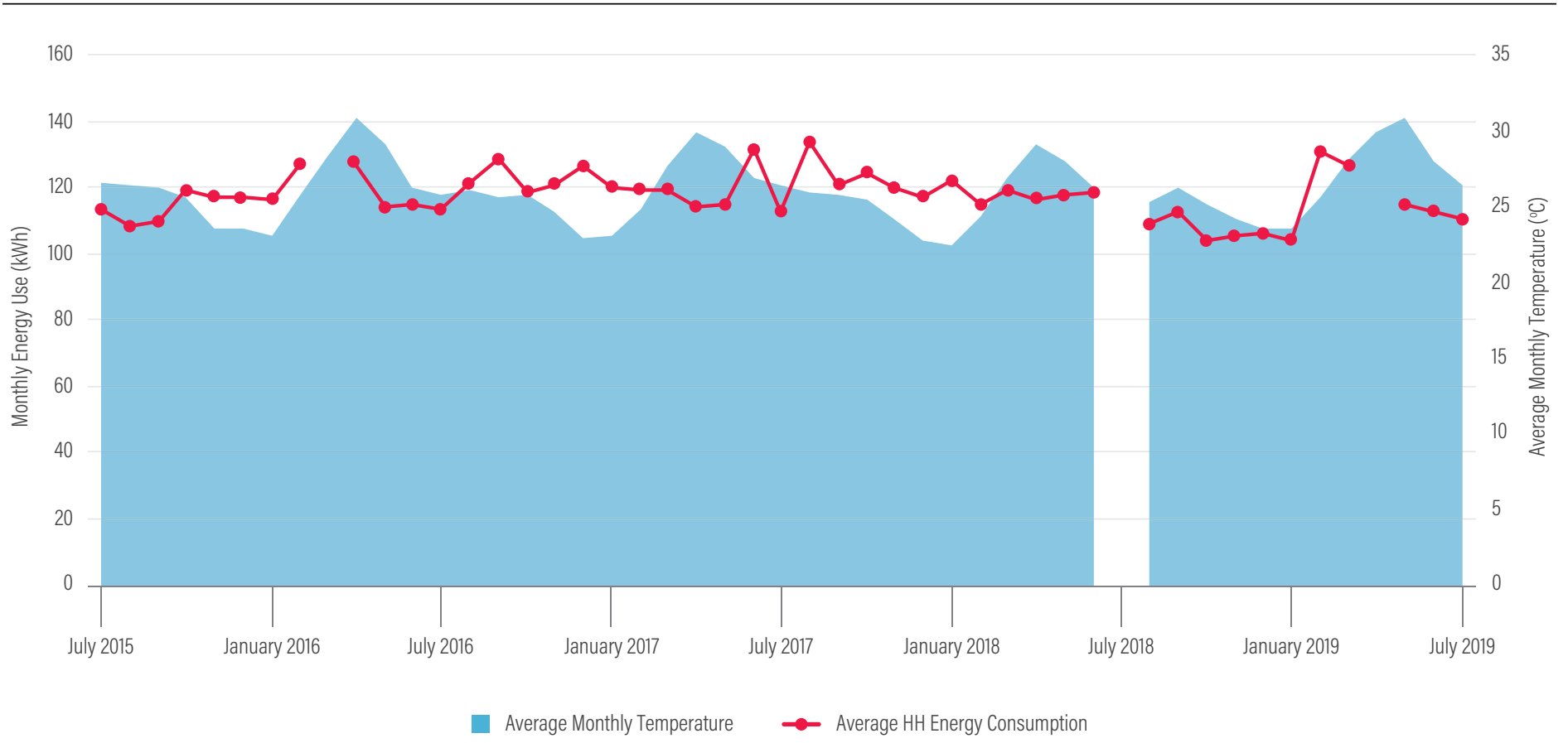

Note: Household electricity consumption data are missing for March 2016 and April 2019; weather data unavailable for July 2018.

Source: WRI Authors. 
Given the lack of significant temperature difference from the pre- to post-intervention periods and the weak association between temperature and energy use, it is unlikely that local weather in Bangalore would explain the changes in energy observed during the period when households received their VR reports.

\section{RESIDENTIAL ENERGY USE TRENDS}

We now turn to the larger state of Karnataka and India as contextualizing data points. We see that monthly consumption from households receiving VR reports decreased from pre- to post-intervention, while per capita electricity consumption in Karnataka and all of India increased over the same period (Figure 5). ${ }^{19}$

\section{STUDY RESULTS}

\section{Sample Overview}

Full Sample $(\mathrm{n}=2,196)$

The full study sample is 2,196 households. The vast majority of households are 1-2 BHKs (84 percent), and 47 percent live in pincodes 560023,560003 , and 560045 . On average, 3.9 people live in each household. ${ }^{20}$

Subsample $(\mathrm{n}=118)$
The subsample of households included in the household survey consists of 118 total households. Mirroring the full sample, the majority of households included in the survey sample are 1-2 BHKs (83 percent), and more than half live in pincodes 560023, 560003, and 560045. Average occupancy per household is 3.6, and there is an almost even distribution of households that were high- and lowenergy consuming before VR. See Appendix B for details on both study samples.

\section{The Effect of VR Reports on Energy Savings}

\section{Question 1.1: Does receiving VR reports change households' energy consumption? What is the magnitude of the change?}

Through a mean comparison, we can see evidence of a significant 7 percent decrease in average monthly energy consumption per household from pre- to post-VR. Interestingly, this finding exactly mirrors the average 7 percent energy savings found in a meta-analysis of similar HER interventions spanning from 1975 to 2012. (Delmas et al. 2013).

In $\mathrm{kWh}$, average household energy consumption dropped from $120 \mathrm{kWh}$ per month pre-VR to 112kWh per month after the VR intervention (Figure 6). ${ }^{21}$

\section{Figure 5 | Annual Energy Consumption within VR Sample (Household) and in Karnataka and India (Per Capita), 2015-2019}

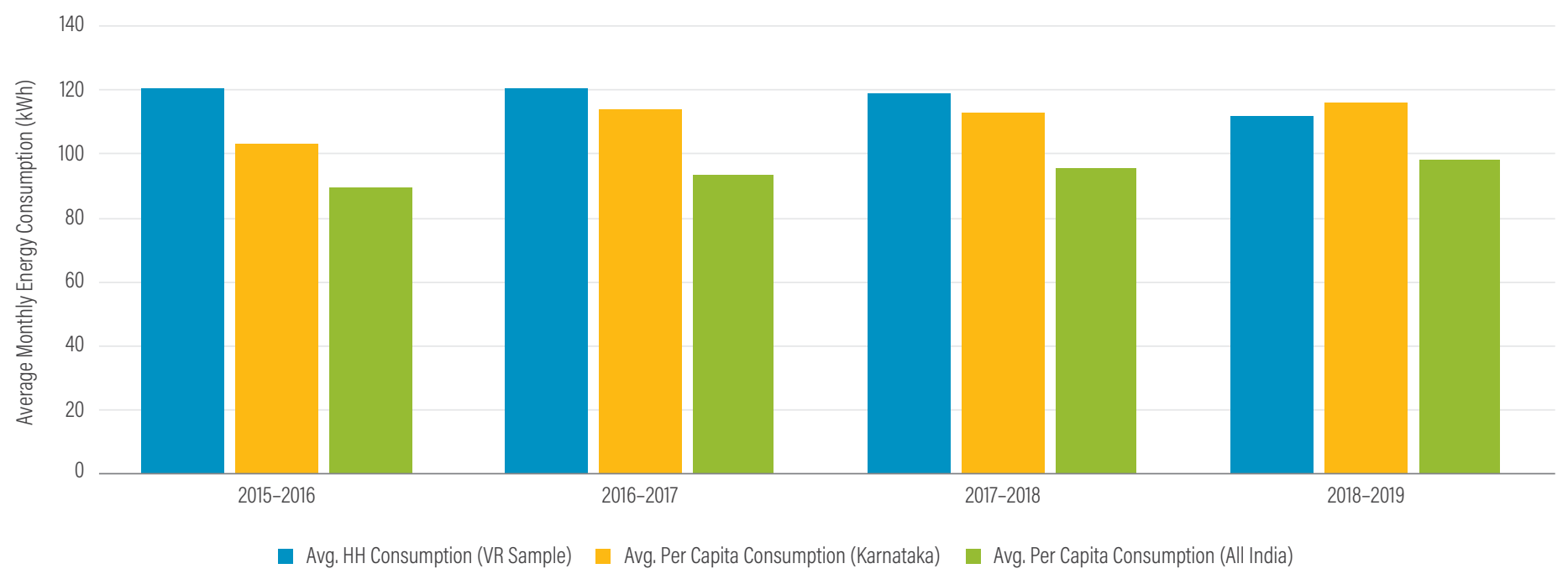

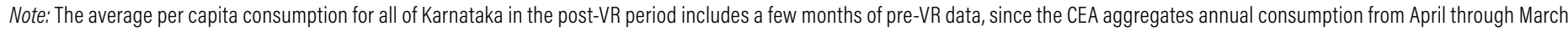
while the VR sample considers July through June.

Source: WRI Authors. 
Figure 6 | Average Household Monthly Energy Use 36 Months Pre-VR (July 2015-June 2018) and 12 Months Post-VR (August 2018-July 2019)

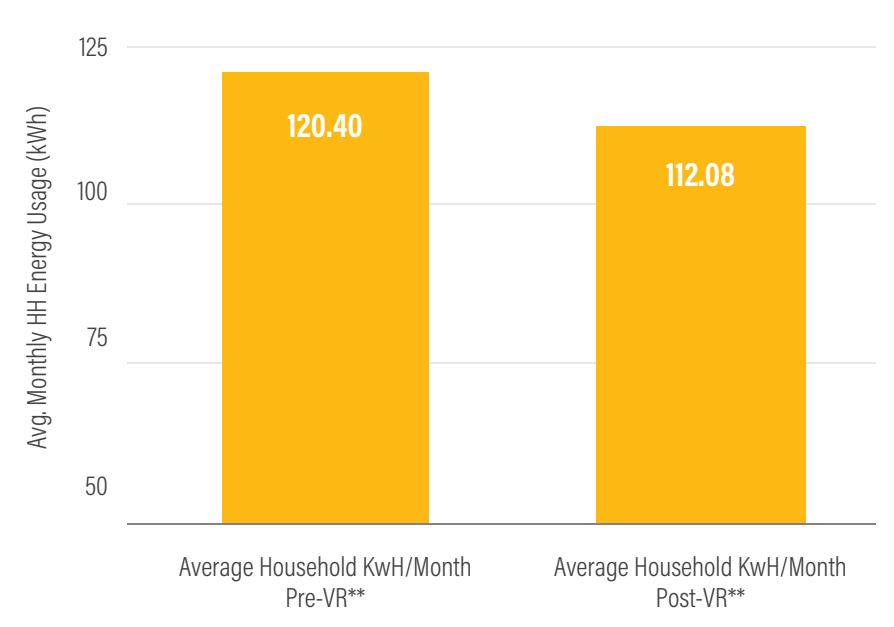

Note: ${ }^{*} \mathrm{p}<, 05,{ }^{* *} \mathrm{p}<, 01,{ }^{* * *} \mathrm{p}<, 001$

Source: WRI Authors.

This energy savings translates to a cost savings of INR 54 per month. While this savings may seem modest at the individual household level, when projected at scale in the state of Bangalore, this translates to a savings of almost $\$ 60$ million each year and over 240 million kWhs saved. (See Appendix A for monetary and energy calculations.) The local utility would have had to increase electricity rates by an estimated 20 percent and wait for at least a year to see a similar decrease in energy consumption. ${ }^{22}$

\section{Question 1.2: Do energy savings vary by demographic characteristics?}

We explore descriptive decreases in consumption by house size (as indicated by BHK), geographic area (as indicated by pincode), and occupancy (as indicated by the number of occupants in a household).

\section{HOUSE SIZE}

In house size, the greatest decrease in energy use was observed among the households with one or two bedrooms, with average savings of 8 percent from pre to post. However, one-bedroom households' savings were not significantly different from households with two to four or more bedrooms. Households with $\mathrm{BHK}=3$ reported the lowest decrease, with average savings of 5 percent.

\section{Figure 7 | Percentage of kWh Saved from Pre-VR Intervention to Post by House Size (BHK)}

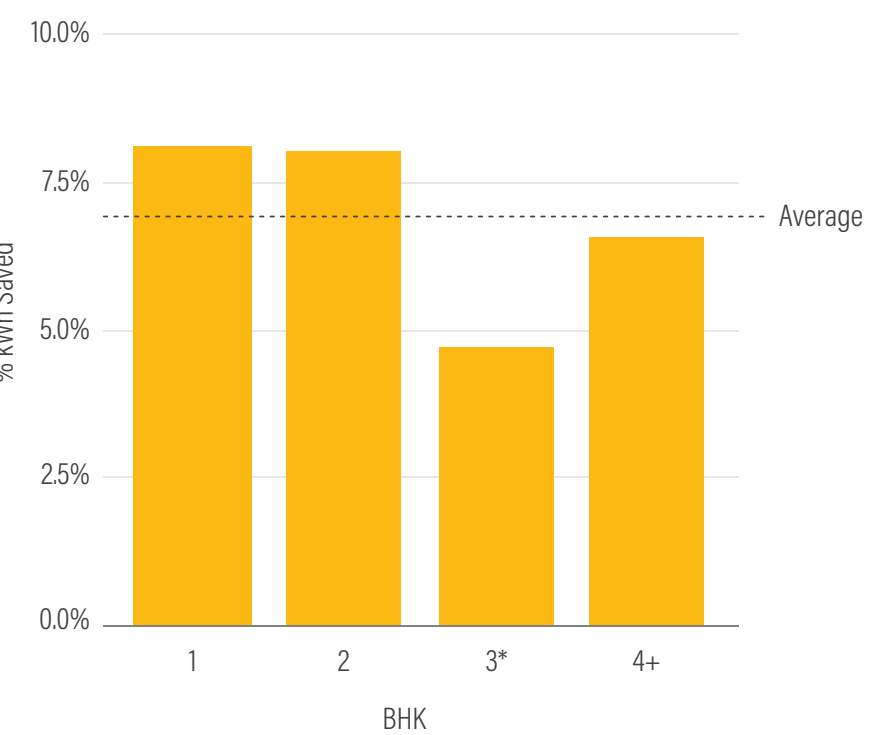

Note: * $p<.05$; $P$-values are calculated from the percentage changes and are compared for significance to the average (6.92\%).

Source: WRI Authors,

\section{GEOGRAPHIC AREA}

We also find that energy savings varied by geographic area with the pincode 560003 corresponding to the area of Malleshwaram in North Bangalore, reporting a significant decrease in consumption (-17 percent), while a slight increase was observed for pincode 560037 corresponding to the area of Marathalli in East Bangalore (o.6 percent increase).

It would be useful to explore the demographic characteristics that correlate with pincode in order to unpack why energy saving seems to vary by neighborhood. Unfortunately, relevant demographic data (household income, education, and employment) are currently unavailable by pincode. This is a ripe area for future study.

\section{OCCUPANCY (PEOPLE PER HOUSEHOLD)}

We find that households with the lowest occupancy rates demonstrate the highest decrease in consumption (saving an average of 22 percent). Households with the highest occupancy ( $7+$ people) save the least on average (saving an average of 3 percent). 
Figure 8 | Percentage of kWh Saved from Pre-VR Intervention to Post-Intervention by Pincode

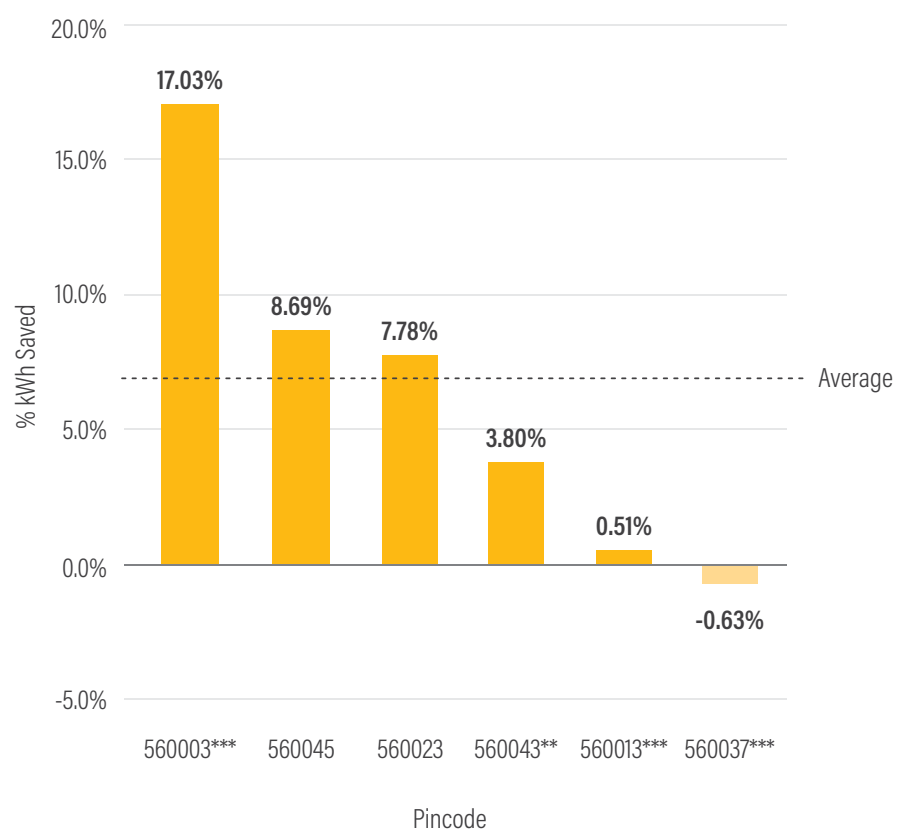

Note: ${ }^{*} \mathrm{p}<, 05,{ }^{* *} \mathrm{p}<, 01,{ }^{* * *} \mathrm{p}<0.01$

Source: WRI Authors.

Figure 9 | Percentage of kWh Saved from Pre-VR Intervention to Post-Intervention by Occupancy

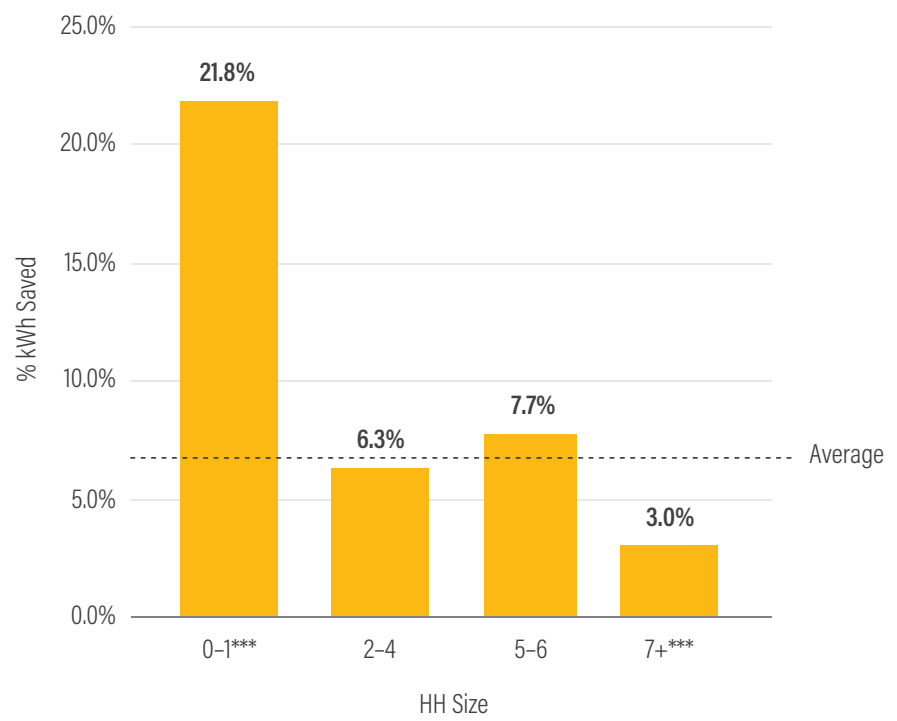

Notes: ${ }^{*} \mathrm{p}<, 05,{ }^{* *} \mathrm{p}<<, 01,{ }^{* * *} \mathrm{p}<, 001 ; 0$ bedroom is a studio,

Source: WRI Authors.
As discussed in detail in the next section, we also find that a significant driver of energy savings (which appears to be driving the variance in savings by household characteristics) is energy usage prior to registering on VR.

\section{Question 1.3: Is there a relationship between prior (pre- VR) energy use and post-VR energy use?}

Exploring energy usage by looking at high- and low-energy users before VR registration, we find that households that were low-energy users before receiving VR reports (defined as households with energy usage below the mean prior to the VR intervention) significantly increased their consumption by 6 percent after registering on VR. Households that were high-energy users before receiving VR reports (defined as households with energy use above the mean prior to the VR intervention) significantly decreased their energy usage by 12 percent (Figure 10).

While these data represent only our sample population, they are similar to previous research from the United States on HERs: Consumers shown to be consuming more than the average bring consumption down, while those shown to be consuming below the average bring their consumption up ${ }^{23}$ (Allcott 2011; Allcott and Rogers 2014; Schultz et al. 2007).

Figure 10 | Change in kWh Usage from Pre-VR Intervention to Post-Intervention by Pre-VR Energy User Type

\section{$10.0 \%$}

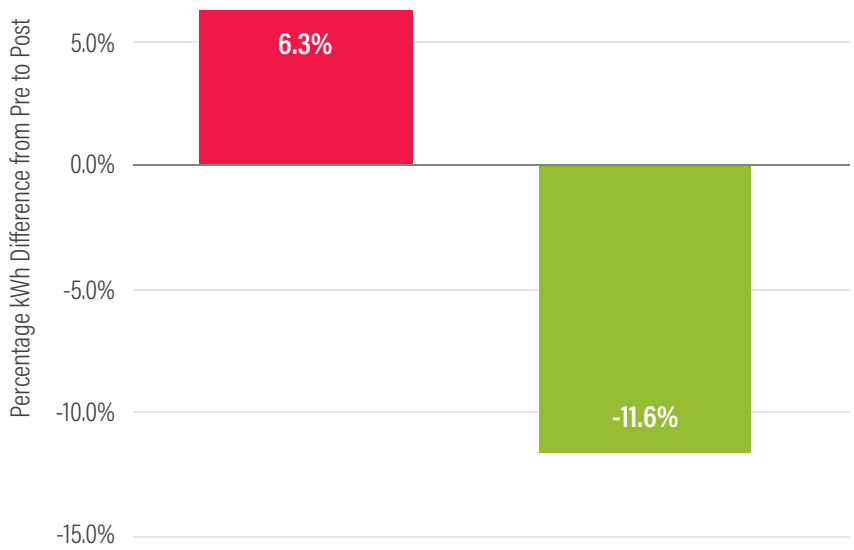

Low-Energy Users before VR ${ }^{* *} \quad$ High-Energy Users before VR **

Note: ${ }^{*} p<.05,{ }^{* *} \mathrm{p}<.01,{ }^{* * *} \mathrm{p}<, 001$

Source: WRI Authors. 
One noted hypothesis for the heterogeneous treatment effects is that this pattern reflects a boomerang effect whereby households told that they are consuming below the mean (below what is normal) bring their consumption up to meet the norm, while households consuming above the mean (above what is normal) bring their consumption down to meet the norm (Ringold 2002; Schultz et al. 2007).

Viewing household energy usage over time, we see that households who were high-energy users pre-VR seemed to be trending toward decreasing energy use prior to joining VR. Lower-energy-consuming households preVR were trending toward a very slight increase in energy use over time.

It is possible that the changes in energy consumption among the pre-VR high-energy-consuming households reflect the acceleration of a preexisting trend rather than the result of a boomerang effect that resulted from the VR intervention, although more rigorous research is needed to fully understand the relationship.
Taking the available household characteristics and historical energy use together, we see only slight differences in energy savings by size of the home and occupancy, but large and significant differences in energy savings by specific geographic areas (560003 and 560037) and by prior energy use (Figure 12).

Finally, we explore a simple estimation of a panel econometric model, the results of which are shown in Appendix E. Here, a household's individual electricity consumption would be explained by the housing (BHK) and household characteristics (occupancy), the monthly average temperature in Bangalore (demand's monthly variability), the average electricity rates for that month, and a proxy of rising incomes using the evolution of India's GDP per capita. The quasi-experimental data include the VR report after July 2018 and therefore offer a before-and-after comparison across households. By having different combinations of explanatory variables, both before the VR sign-up and after the VR reports were received by households, we find the effect of the energy reports would be a reduction of approximately 5.3 percent, close to the reduction of 7 percent obtained from the comparison without controlling for these demand-shifting factors.

\section{Figure 11 Kilowatt Hour Usage per Month by High- and Low-Energy Users Pre-VR ${ }^{24}$}

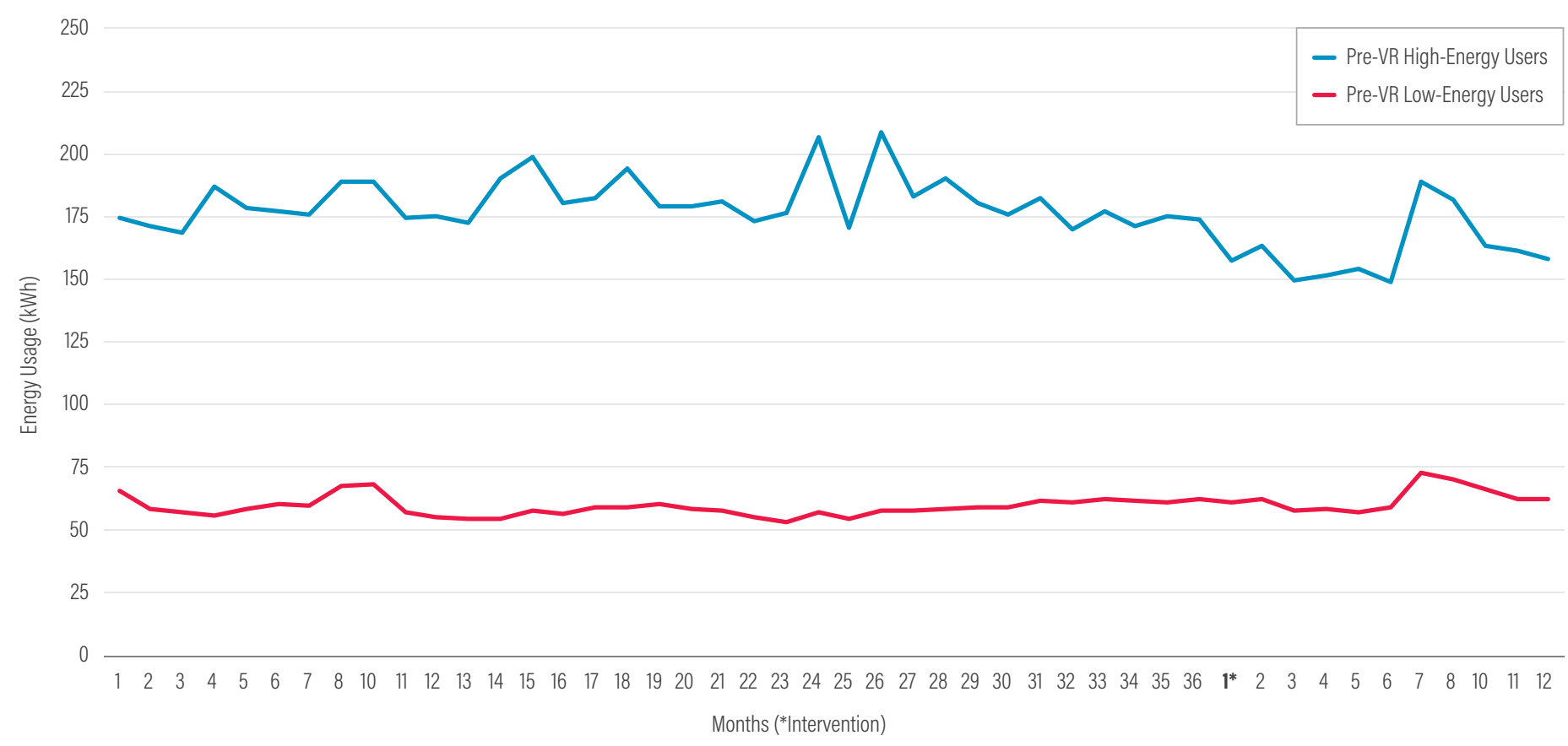

Source: WRI Authors 


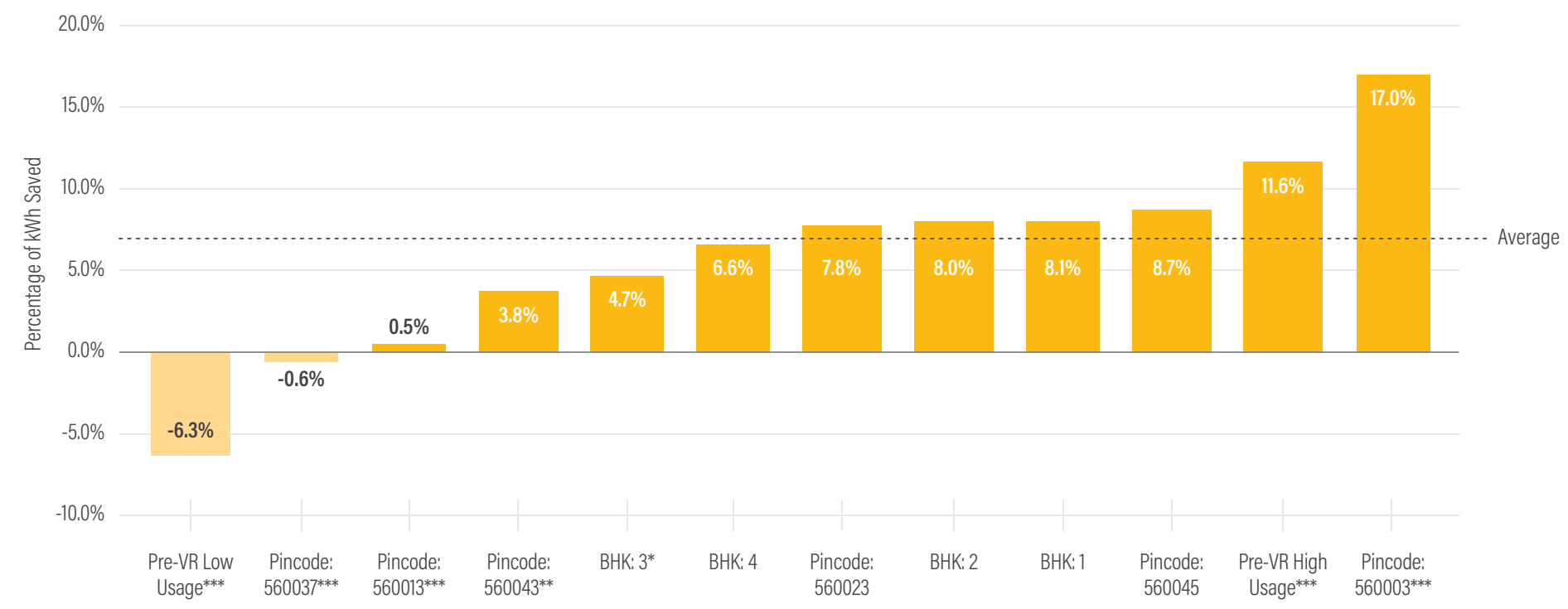

Note: ${ }^{*} p<, 05,{ }^{* *} p<, 01,{ }^{* * *} \mathrm{p}<, 001$

Source: WRI Authors.

\section{Question 1.4: What aspects of the VR report might be driving energy-saving behaviors?}

This section presents results from the household survey subsample. Data, including self-reported data, are imperfect. In self-reported data, in addition to general concerns about response bias, reporting on one's motivations may be particularly unreliable. Evidence indicates that people may not be consciously aware of what actually motivates their behavior. Evidence on the mechanisms or aspects of the HERs underlying the change in energy savings has been understudied, in part because it requires some reliance on imperfect qualitative methods like selfreported data.

Therefore, the survey results are not intended to make a causal argument as to the impact of specific report sections on behavior. Rather, these results are intended to contribute to the literature by diagnostically exploring how VR participants perceive their reports. We hope this initial hypothesis-suggesting evidence can be the starting point for future hypothesis-proving research on the drivers of energy-saving behaviors.

\section{Question 2.1 Do people understand the report and find it motivating? \\ (DRAWN FROM HOUSEHOLD SURVEY DATA)}

To explore the relationship between aspects of the report and energy usage, we begin by asking the first order question: do households understand each section of the report? (Surveyed households were asked, "How clear is the following section of the report?”). To our knowledge, consumers' perceptions of report clarity have not been studied previously. Clarity varies significantly by report section: Sixty-eight percent of respondents report that the Goals for You section is very clear, while only 25 percent report that the Neighborhood Comparison section is very clear (Figure 13).

Respondents report that the sections that motivate them to save energy are the Recommendations section with ideas of how to save in the future, the Goals for You section, and the Historical Consumption section showing households' previous energy usage. While there is evidence that people are not always consciously aware of what motivates their behaviors (Kahneman 2003), it is interesting that we find a relationship between report clarity and motivation: When a section is reported as more clear, it is also reported as more motivating (Figure 14). 
Figure 13 | Percentage of Respondents Reporting Clarity of Each Section of the VR Report

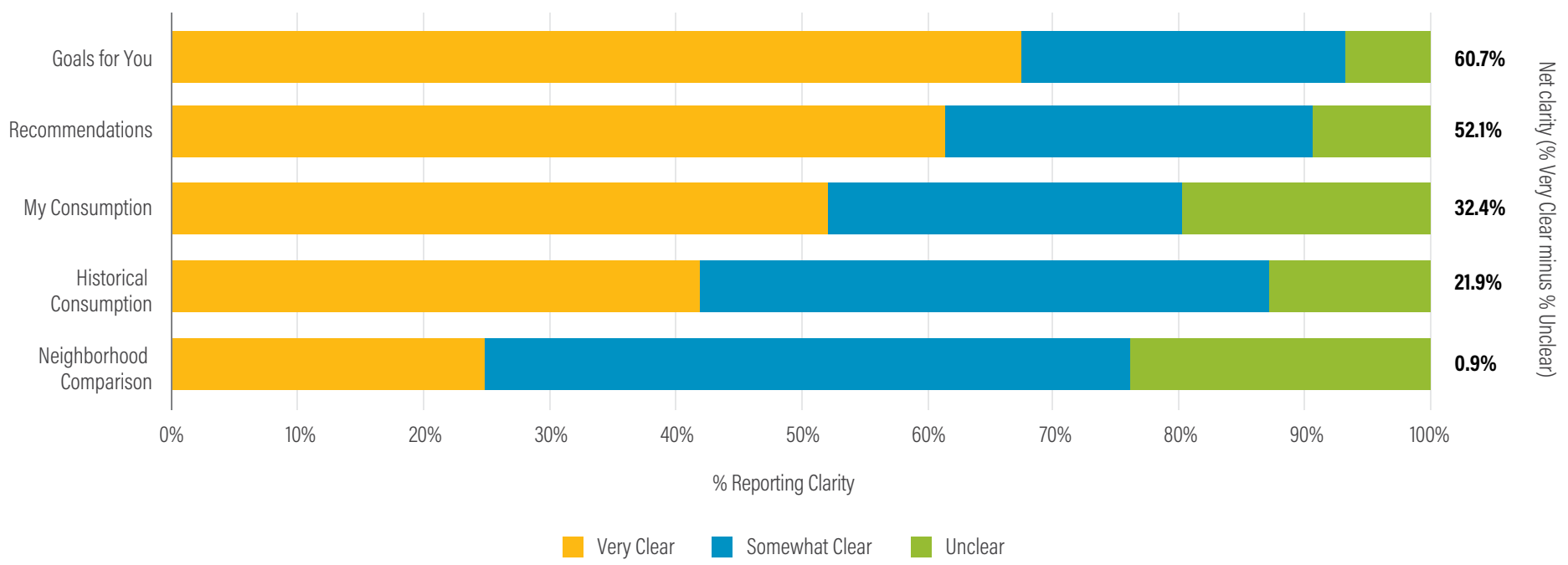

Source: WRI Authors.

Figure 14 | Percentage of Respondents Reporting Clarity (Somewhat and Very Clear) and Motivation of Each Section of the VR Report

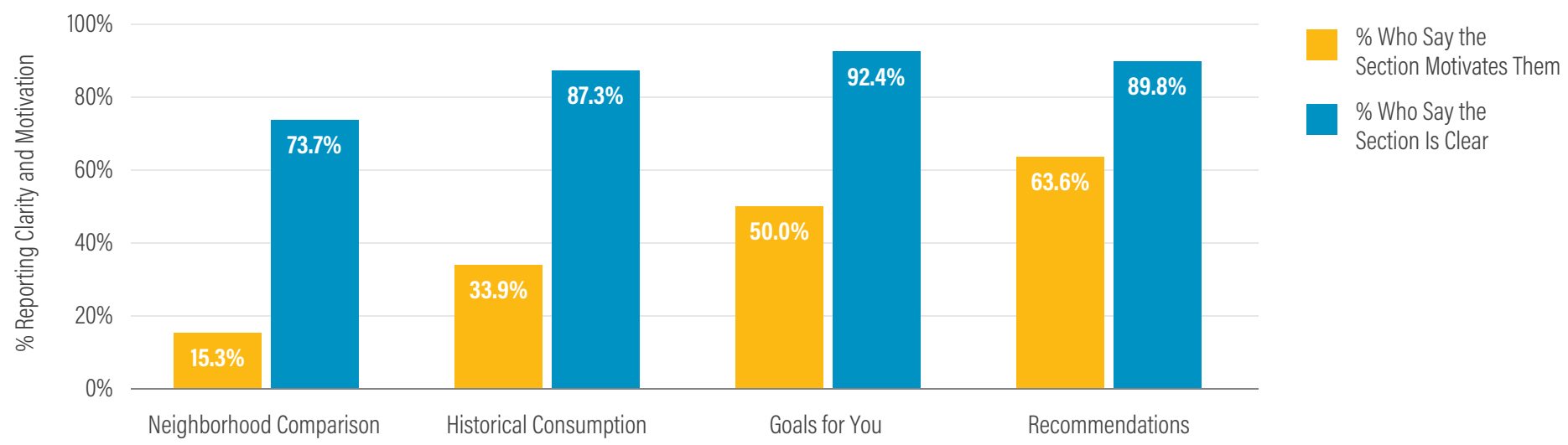

Source: WRI Authors.

\section{THE INFLUENCE OF RECOMMENDATIONS RELATIVE TO} SOCIAL COMPARISONS

Qualitative evidence underlines participants' perceptions that the Recommendation section was especially useful. During one-on-one interviews, participants were asked which parts of the reports were helpful. All (six out of six) interview respondents reported that the Recommenda- tions section was "clear and useful." Asked what sections of the report they focused on and read first, all interview participants noted that they read and focused on the Recommendations section. Many respondents further elaborated that they found other sections hard to under- 
stand. As one participant noted, "The Recommendations section is clear, but other sections don't make sense.” When asked explicitly if there were any sections that they ignored, six out of six respondents reported ignoring the Neighborhood Comparison section as the section and graphs were confusing or didn't make sense. While a very small sample, the consistency of responses between the interview responses and survey findings warrants future exploration.

The initial suggestive evidence that the personalized recommendations were largely described as clear and useful and therefore might have been more influential than the social comparisons (which were more likely to be described as unclear and confusing) supports findings from a 2013 meta-analysis that found that strategies providing individualized energy audits and consulting were comparatively more effective in inducing conservation behavior than strategies providing peer comparison feedback. (Delmas et al. 2013). The personalized recommendations used in the VR reports had a lighter touch than energy audits and consulting, but the underlying insight that specific and personalized information on reducing energy consumption can have a greater impact than social comparisons also warrants further research.

\section{Question 2.2 What aspects of the report, if any, seem to be driving the change in household energy use? \\ (DRAWN FROM HOUSEHOLD SURVEY DATA)}

The only aspect of the report that is significantly and positively correlated with energy saving is reporting yes to the question, "Did you follow the VR report recommendation section while purchasing the appliances?" $(\mathrm{r}=.406$; significant at $\mathrm{p}<.001$ ). While our sample size is modest, our analyses indicate that, regardless of pre-VR energy usage, the more someone follows the recommendations to make the purchase, the more he or she is likely to be an energy saver. See Appendix F for more details.

In correlational analysis, we find evidence that reporting that the recommendations section is clear is correlated, although only weakly, with some capital stock investments, which include both physical stock like energyefficient appliances, as well as consumption capital, which includes a stock of energy-use habits like turning off fans when not in use. Recall that the recommendations section instructed VR participants to invest in specific efficient behaviors and products, and therefore finding this section to be clear might reasonably increase people's ability to act on those recommendations. Specifically, we find that reporting that the recommendations section is clear is positively associated with:

reporting that people in the household "switch off geyser $^{25}$ after use" $(r=0.2179)$;

- reporting that the household "replaced old lights with energy-efficient lights" (clear recommendations: $r$ $=0.2743$ ); and

- reporting "reading the safety and maintenance section of the appliance report" $(\mathrm{r}=0.3308)$.

The correlational analysis does not presume causation; instead, it raises an issue worth further exploration: Can enhanced clarity around specific recommendations for capital stock investments in HERs encourage more energy-efficient investments and greater energy savings? If so, such a costless improvement to HERs (i.e., clearer recommendations) could produce additional energy savings at scale.

\section{Question 3.1 How can VR reports be improved?}

Drawing from the findings of the quantitative data, survey data, and 1:1 interviews, we suggest the following improvements to the VR reports specifically, as well as future HERs that might be developed for an Indian context (though these suggestions may also be broadly applicable):

1. Test and Scale: HERs have the potential to deliver energy and cost savings to households with corresponding benefits for the environment and should be considered for expansion at the state and national level. Scaling efforts should be deployed using a continuous learning approach to test different messages and recruitment techniques in order to ensure improvements in the design and delivery of HERs.

2. Simplify: As many VR participants reported through both one-on-one interviews and survey data, many sections of the report are unclear, especially the neighborhood comparison and historical consumption sections. Providers of HERs should consider designing reports that consist only of

clear information on current usage and costs; comparison with neighbors via one simple icon or message (happy face or green check for energy use below the mean); and

recommendations and goals with a few clear goals and a few actionable and specific recommendations. 
3. Clarify: Expanding on the insight mentioned earlier, even the sections that VR participants reported as the most "clear and motivating" like My Consumption, Recommendations, and Goals for You, still saw fewer than 70 percent of participants reporting that the section was "very clear." Especially with increased stress due to COVID-related health and economic concerns, people have less time and energy resources to devote to deciphering complex information. Therefore, sections that do remain in a slimmed-down HER should be made as clear and easy to understand as possible by using familiar mental models (happy/ sad face or other culturally relevant icons for the comparison with neighbors), clear language, and visual cues.

4. Leverage the Recommendations: All interview respondents reported that the recommendations section is easiest to follow or understand while survey respondents indicated that the recommendations section was the most motivating. Efforts should be spent prioritizing these recommendations and making them as clear and actionable as possible.

5. Focus on High-Energy Users: Focusing on highenergy-using households that are most likely to benefit from HERs can increase the impact of these reports and stretch limited dollars. If utility companies or organizations face limitations on implementation, prioritizing registration of high-energy households may be a way to maximize the program's impact.

\section{Areas for Future Research}

The research detailed in this working paper raises a few critical areas worthy of future research. Specifically, it would be useful to implement randomized control trials testing the impact of reports with various sections. For example, an HER experiment with large samples that allow for disaggregation might compare reports with direct feedback and

treatment 1: recommendations only (no social comparisons);

treatment 2: social comparisons only;

treatment 3: both recommendations and social comparisons; and

control group: sample of households who do not receive HERs.

In addition, collecting data on changes in household income over time and changes in energy use over time would help tease out the relationship, at the household level, of rising incomes and rising energy use among households receiving HERs. Further, collecting microdata on appliance purchasing over the course of receiving HER reports would help tease out the relationship between capital stock investments and energy savings.

Finally, while not an intentional area of study in this research, we do find from our small interview sample that three out of three women interviewed report that their husbands are the primary consumers of the VR report. The question of the differential HER use by gender would be a worthwhile area for future research, especially in contexts where women's literacy rates and household decision-making power may be significantly different than men's.

In response to some of these suggestions and research opportunities, TIDE and WRI India are testing a pilot version of VR (called VR Lite) in which households in one subdivision of the electric utility BESCOM will be provided with a shorter, more focused HER, in line with many of the suggestions mentioned earlier.

\section{Study Limitations}

A program like VR is subject to voluntary response bias. Because the program is voluntary rather than mandatory, those participating in the program are not a representative sample of the general Bangalore population. Rather, people who are interested in saving energy either because of monetary or environmental concerns voluntarily register for VR. In addition, the pre-post design does not control for unobservables that may be driving behavior change over time the way a randomized controlled experiment would. And, as indicated in section 1.4, self-reported survey data are imperfect and may be subject to biased reporting. Finally, this working paper summarizes the impact of HERs over a 12-month period, but metaanalyses indicate that the impact of informational interventions on energy conservation behavior change over time (Delmas et al. 2013). The durability and persistence of the treatment effects of HERs over time merit further investigation.

\section{Policy Application and Scale}

The future application of VR has three possible directions. First, electric utilities can adopt HER-style billing as standard practice. The telescopic tariff system that is widely used in India, where individuals move to higher tariff slabs as their consumption increases, is a signal to 
consumers regarding their consumption behavior and practices. Integrating clear information on consumption and actionable recommendations would strengthen the signal that these tariffs are already sending. Sending consumers this information via the widely used existing system of energy billing is a significant opportunity for impact at scale, as this paper suggests. As utilities consider rolling out HERs at scale, this research suggests a potentially critical adjustment to traditional reports: It is possible that the social norm comparison feature present in most HER reports may not be the driver of energy savings. Adding peer comparison data involves additional data pulls and data analysis. As discussed in the areas for Future Research, new studies could examine the impact of HERs without peer comparisons.

Second, VR-style programs could be scaled via the 100 cities identified by India's Smart Cities Mission. Rolled out in 2015, the mission aims to create energy-efficient urban spaces. The mission's guidelines require that 80 percent of the buildings in the smart cities need to be energy-efficient. New construction can meet this goal by green building from scratch. But for the existing stock, cities will need to find retrofit or behavioral measures to reach the energyefficiency goals. Here again, VR principles and measures could be woven into smart cities plans and schemes by sending VR-style reports to large businesses and employers. The introduction of smart meters in several Indian cities and the data these generate on consumption patterns of households can be used to provide more targeted recommendations, making HERs more scalable.

Finally, voluntary consumer-led efforts, like VR, could continue to grow. As urbanization and household energy consumption increase, VR brings tangible cost savings to those who save electricity. VR could be particularly useful for shared spaces. For example, lighting needs in the common areas of buildings; energy needed to run common facilities like water pumps, elevators, and gymnasiums; and energy needed to power other common facilities, equipment, and appliances shared by residents in apartments and group housing could be obtained more sustainably through the adoption of HER methods.

\section{CONCLUSIONS}

Discovering, testing, and sharing effective ways of decoupling human development from environmental degradation is urgent, especially in emerging economies like India. Evidence from behaviorally designed energy reports that feature actionable recommendations and social norm comparisons have had promising results in decreasing consumption, but they have been understudied in emerging economies where they are arguably most needed. This working paper aims to begin closing this research gap by conducting a quasi-experimental study of the VR program in India and yields three important implications for future research and policy on demand-side interventions.

First, we find evidence that the energy savings associated with HERs reported in prior research in U.S. contexts are similar in scale and applicable and achievable in India. Specifically, we find a significant 7 percent decrease in average monthly energy consumption per household from pre- to post-VR participation. While this savings may seem modest at the individual household level, projected at scale in the state of Karnataka it translates to a savings of almost $\$ 60$ million and more than 604 million $\mathrm{kWh}$ each year and reduction of 0.6 million tonnes of $\mathrm{CO}_{2}$. Given the magnitude of potential impacts at scale, future additional research, funding, and policy efforts focused on designing effective HERs would be well-placed.

Second, we find initial suggestive evidence that the actionable recommendation section of the VR report may be more related to energy savings rather than the social norm comparison section, which significant portions of our sample found to be unclear. We hope this initial hypothesis-suggesting evidence can be the starting point for further exploration on the drivers of energy saving so that future HERs can have an even greater impact. Indeed, we see early evidence that the evolution of Indian HERs is already under way. As a result of the research described in this working paper, VR Lite was introduced in early 2021, using these insights to redesign, condense, and clarify the current HER report. ${ }^{26}$

Finally, this study adds to a growing body of literature on the importance of focusing on the demand side, or human side, of the consumption dilemma. This nuanced understanding of consumer perceptions as a tool to instill longterm behavior change is an increasingly integral part of WRI's work. WRI will continue to work with local partners around the world to conduct more behavioral interventions in the energy domain, building on our findings to design policies that lead to large-scale behavior change with far-reaching implications for sustainability. 


\section{APPENDIX A. CALCULATING COST \\ AND KWH SAVINGS AT SCALE (BANGALORE)}

\section{AMOUNT}

A Average energy saving/household

B Number of domestic consumers of Bangalore (BESCOM 2020a)

C1 Total energy consumption by domestic LT-2 category (BESCOM 2020a)

C2 C1*1000000

D1 Potential energy savings $\left(A^{*} C 2\right)$

D2 $=\mathrm{D} 1 / 1000,000$

E Grid emission factor for $\mathrm{CO}_{2}$ (from CEA 2018)

$\mathrm{CO}_{2}$ emissions savings ( $\left.\mathrm{E}^{*} \mathrm{D} 2\right)$

Average tariff (BESCOM 2020b)

Cost savings

Sources: BESCOM (2020a and 2020b); CEA (2018)
UNIT

$7 \%$

$\begin{array}{cc}95,55,564 & \\ 8,637 & \mathrm{MU} \\ 8,63,65,83,273 & \mathrm{kWh} \\ 60,45,60,829 & \mathrm{kWh} \\ 6,04,561 & \mathrm{MWh} \\ 0.82 & \mathrm{tCO} / \mathrm{MWh} \\ 4,95,739.9 & \mathrm{tCO} \\ 6.93 & \mathrm{INR} \\ 4,18,96,06,546 & \mathrm{INR}\end{array}$

\section{APPENDIX B. FULL SAMPLE AND SUBSAMPLE DESCRIPTIVE DATA}

Table B1 | Full Pre-Post Sample

\section{FULL PRE-POST SAMPLE}

\begin{tabular}{|c|c|c|c|c|c|}
\hline & $\mathbf{N}$ & $\%$ of Study Sample & Avg. Monthly Use Pre-VR (kWh) & Avg. Monthly Use Post-VR (kWh) & Percentage Change \\
\hline All & 2,196 & $100 \%$ & 120.4 & 112.08 & $-6.9 \%$ \\
\hline \multicolumn{6}{|c|}{ House size } \\
\hline BHK 1 & 1,218 & $56 \%$ & 80.94 & 74.39 & $-8.1 \%$ \\
\hline BHK 2 & 634 & $29 \%$ & 134.37 & 123.59 & $-8.02 \%$ \\
\hline BHK3 & 285 & $13 \%$ & 230.89 & 219.97 & $-4.7 \%$ \\
\hline BHK 4 & 59 & $3 \%$ & 251.39 & 234.84 & $-6.6 \%$ \\
\hline \multicolumn{6}{|c|}{ Pincodes } \\
\hline 560023 & 377 & $17 \%$ & 77.72 & 71.67 & $-7.8 \%$ \\
\hline 560003 & 319 & $15 \%$ & 157.59 & 130.75 & $-17.03 \%$ \\
\hline 560045 & 332 & $15 \%$ & 90.58 & 82.71 & $-8.7 \%$ \\
\hline Other Pincodes & 1,168 & $53 \%$ & 132.5 & 129.2 & $-2.5 \%$ \\
\hline \multicolumn{6}{|c|}{ Occupancy } \\
\hline $0-1$ & 60 & $3 \%$ & 100.18 & 78.36 & $-21.8 \%$ \\
\hline $2-4$ & 1,577 & $72 \%$ & 116.13 & 108.79 & $-6.3 \%$ \\
\hline
\end{tabular}


Table B1 | Full Pre-Post Sample (Cont.)

\section{FULL PRE-POST SAMPLE}

\begin{tabular}{l|c|c|c|c|c|}
\hline & N & \% of Study Sample & Avg. Monthly Use Pre-VR (kWh) & Avg. Monthly Use Post-VR (kWh) & Percentage Change \\
\hline $5-6$ & 481 & $22 \%$ & 129.58 & 119.55 & 160.77 \\
\hline $7+$ & 78 & $4 \%$ & 165.82 & $-7.7 \%$ \\
\hline $\begin{array}{l}\text { High-Energy Users } \\
\text { (Pre-VR Sign-Up) }\end{array}$ & 1,098 & $50 \%$ & Historical Energy Use Pre-VR & 161.05 & $-3.04 \%$ \\
\hline $\begin{array}{l}\text { Low-Energy Users } \\
\text { (Pre-VR Sign-Up }\end{array}$ & 1,098 & $50 \%$ & 182.25 & 62.26 \\
\hline
\end{tabular}

Source: WRI Authors.

Table B1 | Household Survey Subsample

HOUSEHOLD SURVEY SUBSAMPLE

\begin{tabular}{|c|c|c|c|c|c|}
\hline & N & $\%$ of Study Sample & Avg. Monthly Use Pre-VR (kWh) & Avg. Monthly Use Post-VR (kWh) & Percentage Change \\
\hline All & 118 & $100 \%$ & 128 & 132.4 & $+3.4 \%$ \\
\hline \multicolumn{6}{|c|}{ House Size } \\
\hline BHK1 & 60 & $51 \%$ & 81.18 & 88.52 & $+9.04 \%$ \\
\hline BHK 2 & 38 & $32 \%$ & 143 & 162 & $+13.3 \%$ \\
\hline BHK3 & 18 & $15 \%$ & 251 & 223.2 & $-11.08 \%$ \\
\hline BHK 4 & 2 & $2 \%$ & 117 & 66.7 & $-43 \%$ \\
\hline \multicolumn{6}{|c|}{ Pincodes } \\
\hline 560023 & 35 & $30 \%$ & 79 & 78.7 & $-0.38 \%$ \\
\hline 560003 & 21 & $18 \%$ & 155 & 161.86 & $+4.4 \%$ \\
\hline 560045 & 12 & $10 \%$ & 94.5 & 98.13 & $+3.8 \%$ \\
\hline Other Pincodes & 50 & $42 \%$ & 158 & 165.83 & $+5 \%$ \\
\hline \multicolumn{6}{|c|}{ Occupancy } \\
\hline $0-1$ & 4 & $3 \%$ & 65.5 & 86.32 & $+31.8 \%$ \\
\hline $2-4$ & 92 & $78 \%$ & 130 & 139.57 & $+7.36 \%$ \\
\hline $5-6$ & 20 & $17 \%$ & 139 & 117,18 & $-15.7 \%$ \\
\hline $7+$ & 2 & $2 \%$ & 28 & 46.85 & $+67.3 \%$ \\
\hline \multicolumn{6}{|c|}{ Historical Energy Use Pre-VR } \\
\hline $\begin{array}{l}\text { High-Energy Users } \\
\text { (Pre VR Sign-Up) }\end{array}$ & 64 & $54 \%$ & 186.75 & 175.77 & $-5.9 \%$ \\
\hline $\begin{array}{l}\text { Low-Energy Users } \\
\text { (Pre-VR Sign-Up) }\end{array}$ & 54 & $46 \%$ & 57.94 & 81 & $+39.8 \%$ \\
\hline
\end{tabular}

Source: WRI Authors. 


\section{APPENDIX C. RESEARCH QUESTIONS, SUB-QUESTIONS, AND METHODS}

\begin{tabular}{|c|c|c|c|c|}
\hline \# & RESEARCH QUESTION & METHOD & DATA USED & SAMPLE SIZE \\
\hline Q1.1 & $\begin{array}{l}\text { Does receiving VR reports change households' energy } \\
\text { consumption? What is the magnitude of the change? }\end{array}$ & \multirow[t]{3}{*}{$\begin{array}{l}\text { Pre-VR to Post-VR energy } \\
\text { usage comparison }\end{array}$} & \multirow[t]{3}{*}{$\begin{array}{l}\text { BESCOM } \\
\text { administrative data }\end{array}$} & \multirow[t]{3}{*}{2,196} \\
\hline Q1.2 & Do energy savings vary by demographic characteristics? & & & \\
\hline Q1.3 & $\begin{array}{l}\text { Is there a relationship between prior (pre-VR) energy use } \\
\text { and post-VR energy use? }\end{array}$ & & & \\
\hline \multicolumn{5}{|c|}{ 2. What mechanisms (aspects of the VR report) might be driving energy-saving behaviors? } \\
\hline Q2.1 & Do people understand the report and find it motivating? & \multirow{2}{*}{$\begin{array}{l}\text { Household surveys and } \\
\text { administrative data }\end{array}$} & \multirow[t]{2}{*}{$\begin{array}{l}\text { Household survey results + } \\
\text { BESCOM administrative data }\end{array}$} & \multirow[t]{2}{*}{118} \\
\hline Q2.2 & $\begin{array}{l}\text { What aspects of the report, if any, seem to be driving the } \\
\text { change in household energy use? }\end{array}$ & & & \\
\hline \multicolumn{5}{|c|}{ 3. How can future VR reports be improved, especially in light of COVID realities? } \\
\hline Q3.1 & How can VR reports be improved? & Mixed-methods synthesis & $\begin{array}{l}\text { Household surveys, interviews, } \\
\text { and administrative data }\end{array}$ & $\begin{array}{l}6 \text { interviews, } 118 \text { surveys, } \\
\text { 2,196 admin. data }\end{array}$ \\
\hline
\end{tabular}

Note on analysis and data cleaning: Occasionally, BESCOM administrative data reported zero energy use for households during the pre-VR or post-VR period, indicating either that households

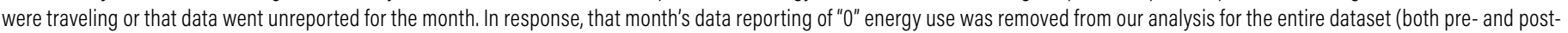

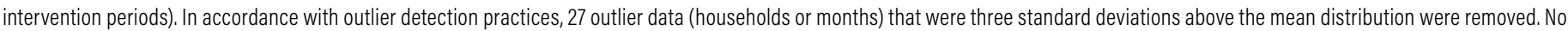

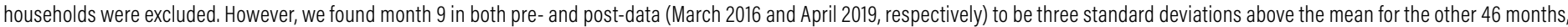
and it was therefore removed. We explored possible explanations for consumption difference in month 9 , including weather extremes and price changes, but neither were explanatory.

Source: WRI Authors.

\section{APPENDIX D, VR HOUSEHOLD PHONE SURVEY}

Questions

1. Do you receive the VidyutRakshaka report?

2. Do you read the VR reports? (If yes, continue; if no, can we speak to the member of the household who does read the reports?)

3. Do you agree to participate in this survey?

4. How clear are the following sections? [My Consumption details]

5. How clear are the following sections? [Benchmarking with Neighbours]

6. How clear are the following sections? [Historical Comparison]

7. How clear are the following sections? [Goals for You]

8. How clear are the following sections? [Recommendations]

9. Which of the following recommendations have you implemented?

10. For how many hours do you use Geyser?

11. How many appliances do you use during peak load hours? (between 6 a.m. and 9 a.m.; 6 p.m. and 9 p.m.)

12. Which section of the report motivates you to follow recommendations and save electricity?

13. Do you follow any other recommendations for saving electricity? If yes, please share.

14. Have you noticed a reduction in the electricity bill after you started following the reports?
15. What are new appliances that you have purchased during the last year?

16. Did you follow the VR report recommendations while purchasing the appliances?

17. Have you noticed an increase in the electricity bill after you started using the new appliances?

18. If yes, was the increase in electricity bill within your expectations?

19. Do you suggest any changes to the existing contents or to the flow of the content in the report?

20. If yes, can you briefly explain them?

21. Considering printing costs and waste of paper, we would like to use digital reports. Will you be interested in reports shared through e-mail or app or a password-controlled Website?

22. Do you have consistent access to e-mail or phone in order to access these reports?

23. During the lockdown period (March and April), usage of which of the following appliances increased?

24. Was the increase in electricity bill during lockdown within your expectation? 


\section{APPENDIX E. PANEL ESTIMATION OF}

\section{HOUSEHOLD CONSUMPTION OF ELECTRICITY}

\section{AMONG VR PARTICIPANTS IN BANGALORE}

The specifications that include the variable number of months receiving VR reports (1 and 2) would be interpreted as the longer-term effects, either reinforcing long-run decisions, or dimming the initial behavioral effect. The positive coefficient means the effect would be wearing out fast over time; however, inspection of Figure 11 (p. 18) | kWh usage per month by pre-VR energy user type shows a bump observed in months 7-8 (February-March 2019) that seems to be driving this effect, a fact that could correspond to not-modeled seasonality.

Table E-1 | Panel Estimation of Household Consumption of Electricity among VR Participants in Bangalore

\begin{tabular}{|c|c|c|c|}
\hline DEPENDENT VARIABLE: & $\begin{array}{l}\text { (1) CONSUMPTION } \\
\text { (LOG) (UNITS KWH/MONTH) }\end{array}$ & $\begin{array}{l}\text { (3) CONSUMPTION } \\
\text { (LOG) (UNITS KWH/MONTH) }\end{array}$ & $\begin{array}{l}\text { (3) CONSUMPTION } \\
\text { (LOG) (UNITS KWH/MONTH) }\end{array}$ \\
\hline Explanatory Variables & Observations $=81,147$ & Observations $=81,147$ & Observations $=81,147$ \\
\hline Constant & $\begin{array}{c}2.635^{* * *} \\
(0.283)\end{array}$ & $\begin{array}{c}3.347 * * * \\
(0.068)\end{array}$ & $\begin{array}{c}4.769 * * * \\
(0.020)\end{array}$ \\
\hline VR-report received (yes=1/no=0) & $\begin{array}{c}-0.148 * * * \\
(0.020)\end{array}$ & $\begin{array}{c}-0.127^{* * *} \\
(0.020)\end{array}$ & $\begin{array}{c}-0.054^{* * *} \\
(0.020)\end{array}$ \\
\hline \# months receiving VR reports & $\begin{array}{c}0.016^{* * *} \\
(0.020)\end{array}$ & $\begin{array}{c}0.015^{* * *} \\
(0.020)\end{array}$ & \\
\hline Average Temperature $\left({ }^{\circ} \mathrm{C}\right)$ & $\begin{array}{c}0.021^{* * *} \\
(0.002)\end{array}$ & $\begin{array}{c}0.021^{* * *} \\
(0.002)\end{array}$ & $\begin{array}{c}0.065^{* * *} \\
(0.025)\end{array}$ \\
\hline Size, 2 bedrooms (vs BHK1) & $\begin{array}{c}0.511^{* * *} \\
(0.035)\end{array}$ & $\begin{array}{c}0.511^{* * *} \\
(0.035)\end{array}$ & $\begin{array}{c}0.510^{* * *} \\
(0.036)\end{array}$ \\
\hline Size, 3 bedrooms (vs BHK1) & $\begin{array}{c}1.123 * * * \\
(0.042)\end{array}$ & $\begin{array}{c}1.125^{* * *} \\
(0.042)\end{array}$ & $\begin{array}{c}1.124 * * * \\
(0.046)\end{array}$ \\
\hline Size, 4+ bedrooms (vs BHK1) & $\begin{array}{c}1.101^{\text {*** }} \\
(0.101)\end{array}$ & $\begin{array}{c}1.100 \text { *** } \\
(0.101)\end{array}$ & $\begin{array}{c}1.101^{* * *} \\
(0.102)\end{array}$ \\
\hline Dwelling occupancy (individuals) & $\begin{array}{c}0.064^{* * *} \\
(0.018)\end{array}$ & $\begin{array}{c}0.041^{* * *} \\
(0.015)\end{array}$ & $\begin{array}{c}0.029 * * * \\
(0.014)\end{array}$ \\
\hline GDP per capita & $\begin{array}{l}-0.0001 \\
(0.001)\end{array}$ & $\begin{array}{c}-0.0003 \\
(0.001)\end{array}$ & $\begin{array}{l}-0.0001 \\
(0.001)\end{array}$ \\
\hline Electricity rates in Karnataka & $\begin{array}{c}0.154^{* * *} \\
(0.059)\end{array}$ & & \\
\hline R2 Adjusted: & 0.027 & 0.027 & 0.025 \\
\hline F-statistic: & $1261.75^{* * *}$ & $1229.61^{* * *}$ & $1117.28^{* * *}$ \\
\hline
\end{tabular}

Source: WRI Authors. 


\section{APPENDIX F, CROSS-TABULATION: ENERGY \\ SAVING BY HOUSEHOLD CHARACTERISTIC \\ AND APPLIANCE RECOMMENDATIONS}

\section{ENERGY USAGE (KWH)}

Did you follow the VR report recommendations while purchasing the appliances?

Below Avg. Energy Users Pre-VR

Above Avg. Energy Users Pre-VR

Yes

8

$-21.7$

$n=13$

$n=30$

No

17

15.9

$n=22$

$n=13$

I don't know

40.57

$-12.37$

$n=19$

$n=21$

Energy use calculated as post-VR usage-pre-VR usage (i.e., negative numbers indicate decrease in electricity consumption)

Numbers in italics indicate the number of respondents from the sample.

Source: WRI Authors. 
1 According to the U.S. Energy information Administration, energy efficiency refers to use of technology that requires less energy to perform the same function. Energy conservation is any behavior that results in the use of less energy.

2 Vidyut Rakshaka translates as "electricity savior."

3 Quasi-experimental study: experiment or designed intervention that aims to estimate causation but does not use random assignment.

4 In the same time period, the population in India has grown by over 30 percent while per capita income has quadrupled (World Bank n.d; Macrotrends n.d).

5 This effect is partially compensated for by reduced emissions from traditional cooking fuels.

6 Allcott 2011; Allcott and Rogers 2013; OPower 2016; Schultz et al. 2007.

7 Descriptive norms describe what others do. Injunctive norms refer to perceptions of what is approved or disapproved of by others (Reno et al. 1993).

8 Social scientists have used injunctive norms to counter this effect by presenting below-average use as a behavior that is socially approved of. In the classic study by Shultz et al. (2007), a happy face was featured to reinforce low-consuming households' efficient behavior, and a sad face was featured to convey social disapproval for above-average consuming homes. Adding the injunctive message eliminated the boomerang effect.

9 In India, these are referred to as BHK-Bedroom Hall and Kitchen. A 2-BHK refers to 2 bedrooms, 1 hall, and kitchen.

10 Pincode or the Postal Index Number is a six-digit code used by the Indian postal service. Each individual pincode broadly captures a distinct geographic area within the country.

11 The optimal model compares the household use against "optimal" use. The average ownership and usage of different types of appliances (classified into lighting, heating, cooling, appliances, and entertainment) is modeled for each BHK category. Each consumer is then benchmarked in its BHK category based on this optimal model. This optimal model was iterated periodically based on current data or usage patterns.

12 Energy use as presented in consumers' VR reports has been corrected for temperature, which in Bangalore does not significantly vary by season.

13 Reports are sent in English.

14 As noted in endnote 11, the optimal model compares the household use against "optimal" use. The average ownership and usage of different types of appliances (classified into lighting, heating, cooling, appliances, and entertainment) is modeled for each BHK category. Each consumer is then benchmarked in its BHK category based on this optimal model. This optimal model was iterated periodically based on current data or usage patterns.

15 A notable exception is Dolan and Metcalfe (2013), which attempted to isolate, among other treatments, the impact of social norm messaging from energy-saving tips (or generic information) in order to explore whether prior studies had "overstated the importance of norms and understated the impact of basic information."
16 At the start of the phone survey, participants were asked, "Do you read the VR reports? (If yes, continue; if no, can we speak to the member of the household who does read the reports?)"

17 Because reliable comparison data was not available for Bangalore we use data from Karnataka.

18 In 2015 terms, adjusted using the World Bank annual percent of inflation on consumer prices.

19 There is a slight lag in the yearly data being compared, since the VR sample is analyzed from July through June, while the CEA data is aggregated from April to March. The state- and national-level per capita estimates of energy use in the text consider gross electrical energy availability divided by the mid-year population figures and therefore do not single out residential consumption alone. Nonetheless, the share of energy sold to domestic users has generally remained stable over the same period, assuring that the trend in per capita averages reflects growing residential consumption and not only increased use in other sectors.

20 Only VR customers who remained in the same home during the threeyear study period were included in the analysis.

21 We indicate statistical significance within each graph; * indicating $p<1$; ${ }^{* *}$ indicating $p<, 05$; and ${ }^{* * *}$ indicating $p<.01$.

$22 \mathrm{~A} 1$ percent increase in real electricity price results in a small 0.02 percent decrease on an average in the state Electrical Energy Requirement in the short run at the all-India level. The CEA also provides price elasticity by region, given India's regional variation. For the southern region, where Bangalore is located, the price elasticity modeled by CEA is -0.12 in the short run and -0.36 in the long run. Given this short-term price increase, using -0.12 , a 58.3 percent increase in electricity prices will be needed.

23 Schultz et al. (2007) found that households above the norm decreased consumption by $1.2 \mathrm{kWh}$ while households below the norm increased their consumption by $.89 \mathrm{kWh}$. In data across OPower's experiments (2001 and 2014), the average monthly savings is approximately 6 percent for high-energy users and close to zero for low-energy users.

24 In accordance with outlier detection practices, outlier data (households or months) that were three standard deviations above the mean distribution were removed. No households were excluded. However, we found month 9 in both pre- and post-data (March 2016 and April 2019, respectively) to be three standard deviations above the mean for the other 46 months, and it was therefore removed.

25 In other country contexts, geysers are referred to as electric water heaters.

26 Specifically, in response to this research, TIDE is considering revising reports to be more visual and present energy use as a cost in rupees rather than in kWh units.

27 There is "a strong beneficial effect of removal of extreme scores. Accuracy tended to increase significantly and substantially, and errors of inference tended to drop significantly and substantially once extreme scores were removed" (Osbourne and Overbay 2004). 
Ahmad, Sohail, Giovanni Baiocchi, and Felix Creutzig. 2015. "CO 2 Emissions from Direct Energy Use of Urban Households in India." Environmental Science \& Technology 49 (19): 11312-20.

Allcott, H. 2011. "Social Norms and Energy Conservation." Journal of Public Economics 95 (9-10): 1082-1095.

Allcott, $H_{1}$, and S. Mullainathan. 2010. "Behavior and Energy Policy." Science 327 (5970): 1204-1205.

Allcott, $H_{1}$, and T. Rogers. 2014. "The Short-Run and Long-Run Effects of Behavioral Interventions: Experimental Evidence from Energy Conservation." American Economic Review 104 (10): 3003-3037.

Bali, Nidhi, Sidhartha Vermani, and Vaishali Mishra. 2020. Electricity Access and Benchmarking of Distribution Utilities in India, New Delhi: Smart Power India-Powered by the Rockefeller Foundation https://smartpowerindia.org/ Media/WEB_SPI_Electrification_16.pdf.

BESCOM (Bangalore Electricity Supply Company). 2020a. "BESCOM in Brief." Bangalore, India: BESCOM.

BESCOM. 2020b. "Proposed Electric Power Tariff-FY-21 General Terms and Conditions of Tariff: (Applicable to Both HT and LT)." Bangalore, India: BESCOM.

Capuano, L. 2020. International Energy Outlook. Washington, DC: U.S. Energy Information Administration. https://www.eia.gov/outlooks/ieo/pdf/ie02020. pdf.

CEA (Central Electricity Authority). 2018. All India Electricity Statistics. New Delhi, India: Ministry of Power. https://cea.nic.in/wp-content/uploads/ baseline/2020/07/user_guide_ver14.pdf. Accessed: April 17, 2021.

CEA. 2019. Long-Term Electricity Demand Forecasting. Ministry of Power. https://cea.nic.in/old/reports/others/planning/psif/Long_Term_Electricity_ Demand_Forecasting_Report.pdf.

Chetty, Raj, Adam Looney, and Kory Kroft. 2009. "Salience and Taxation: Theory and Evidence." American Economic Review 99 (4): 1145-77. https://doi. org/10.1257/aer.99.4.1145.

Chunekar, A., and S. Mulay. 2017. Trends in India's Residential Electricity Consumption. Centre for Policy Research. November 7. https://www.cprindia. org/news/6519. Accessed: April 17, 2021.

Cialdini, R.B., C.A. Kallgren, and R.R. Reno. 1991. "A Focus Theory of Normative Conduct." Advances in Experimental Social Psychology 24: 201-234.

Conceição, Pedro. 2019. Human Development Report 2019. United Nations Development Programme. http://hdr.undp.org/sites/default/files/hdr2019.pdf.

Cumming, G.S., and S. von Cramon-Taubadel. 2018. "Linking Economic Growth Pathways and Environmental Sustainability by Understanding Development as Alternate Social-Ecological Regimes." Proceedings of the National Academy of Sciences 115 (38): 9533-9538.

Delmas, Magali, Miriam Fischlein, and Omar Asensio. 2013، "Information Strategies and Energy Conservation Behavior: A Meta-analysis of Experimental Studies from 1975 to 2012." Energy Policy 61: 729-739.
Dolan, Paul, and Robert Metcalfe. 2012. "Measuring Subjective Wellbeing: Recommendations on Measures for Use by National Governments." Journal of Social Policy 41 (2): 409-27.

Fischer, Corinna. 2008. "Feedback on Household Electricity Consumption: A Tool for Saving Energy?" Energy Efficiency 1 (1): 79-104.

Gerber, A.S., and T. Rogers. 2009. "Descriptive Social Norms and Motivation to Vote: Everybody's Voting and So Should You." The Journal of Politics 71 (1): 178-191.

Goldstein, N.J., R.B. Cialdini, and V. Griskevicius. 2008. "A Room with a Viewpoint: Using Social Norms to Motivate Environmental Conservation in Hotels." Journal of Consumer Research 35 (3): 472-482.

Hechter, Michael, and Karl-Dieter Opp, eds. 2001. Social Norms. New York: Russell Sage Foundation.

Hojjati, B. 2019. "Global Energy Consumption Driven by More Electricity in Residential, Commercial Buildings." October 29. U.S. Energy Information Administration. https://www.eia.gov/todayinenergy/detail.php?id=41753. Accessed: April 17, 2021.

IMF (International Monetary Fund). 2021. "World Economic Outlook Update." April 2021. https://www.imf.org/en/Publications/WE0/Issues/2021/03/23/ world-economic-outlook-april-2021.

IEA (International Energy Agency). 2021. India Energy Outlook 2021. https:// www.iea.org/reports/india-energy-outlook-2021. Accessed: April 17, 2021.

Kahneman, Daniel. 2003. "Maps of Bounded Rationality: Psychology for Behavioral Economics." American Economic Review 93 (5): 1449-1475.

Kahneman, Daniel, and Amos Tversky. 1979. "Prospect Theory: An Analysis of Decision under Risk." Econometrica 47 (2): 263. https://doi. org/10.2307/1914185.

KERC (Karnataka Electricity Regulatory Commission), 2019. Tariff Order 2019. Bangalore, India: Government of Karnataka.

Klaes, Matthias, and Esther-Mirjam Sent. 2b005. "A Conceptual History of the Emergence of Bounded Rationality." History of Political Economy, 37 (1): 27-59. doi:10.1215/00182702-37-1-27.

Macrotrends. n.d. India GNI Per Capita 1962-2021. https://www.macrotrends. net/countries/IND/india/gni-per-capita. Accessed: April 17, 2021.

Marois, R., and J. Ivanoff. 2005. "Capacity Limits of Information Processing in the Brain." Trends in Cognitive Science 9 (6): 296-305.

MOSPI (Ministry of Statistics and Program Implementation). 2019. Energy Statistics. Central Statistics Office, Federal Government of India. http://mospi. nic.in/. Accessed: April 17, 2021.

Munasinghe, Mohan. 1981. "Optimal Electricity Supply." Energy Economics 3: 140-152. 10.1016/0140-9883(81)90035-9.

Myhrvold, Nathan P., and Ken Caldeira. 2012. "Greenhouse Gases, Climate Change and the Transition from Coal to Low-Carbon Electricity." Environmental Research Letters 7 (1): 014019. 
OECD (Organisation for Economic Co-operation and Development). 2019. "India Economic Snapshot." In Economic Survey of India: Executive Summary, Organisation for Economic Co-operation and Development, http://www. oecd.org/economy/india-economic-snapshot/. Accessed: April 17, 2021.

Opower. 2016. "Opower's Utility Partners Save 11 Terawatt-Hours of Energy." https://opower.com/news-and-press/opowers-utility-partners-save-11terawatt-hours-of-energy/. Accessed: April 17, 2021.

Osborne, Jason W., and Amy Overbay. 2004. "The Power of Outliers (and Why Researchers Should Always Check for Them)." Practical Assessment, Research, and Evaluation 9 (1): 6.

Reno, R., R. Cialdini, and C.A. Kallgren. 1993. "The Transsituational Influence of Social Norms." Journal of Personality and Social Psychology 64: 104-112.

Ringold, Debra Jones. 2002. "Boomerang Effects in Response to Public Health Interventions: Some Unintended Consequences in the Alcoholic Beverage Market." Journal of Consumer Policy 25 (1): 27-63.

Rivas Calvete, S, B. Cuniberti, and P. Bertoldi. 2016. Effective Information Measures to Promote Energy Use Reduction in EU Member States." EUR 27997 EN. Luxembourg: Publications Office of the European Union. JRC100661.

Schultz, P.W., J.M. Nolan, R.B. Cialdini, N.J. Goldstein, and V. Griskevicus. 2007 "The Constructive, Destructive, and Reconstructive Power of Social Norms." Psychological Science 18 (5): 429-434.

Schwartz, Shalom H. 1977. "Normative Influences on Altruism." Advances in Experimental Social Psychology 10: 221-79.

Sheeran, P., and C. Abraham. 2003. "Mediator of Moderators: Temporal Stability of Intention and the Intention-Behavior Relation." Personality and Social Psychology Bulletin 29: 205-215.

Shukla, Yashkumar, Rajan Rawal, and Sophie Shnapp. 2014. "Residential Buildings in India: Energy Use Projections and Savings Potentials." Growth 800: 1000 .

Simon, Herbert A. 1957. Models of Man. New York: John Wiley.

Sudarshan, A. 2017. "Nudges in the Marketplace: The Response of Household Electricity Consumption to Information and Monetary Incentives." Journal of Economic Behavior and Organization 134: 320-335. https://doi.org/10.1016/j. jebo.2016.12.015.

World Bank. n.d. Population, Total-India. https://data.worldbank.org/ indicator/SP.POP.TOTL?locations=IN. Accessed: April 17, 2021.

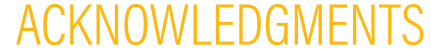

We are pleased to acknowledge our institutional strategic partners that provide core funding to WRI: the Netherlands Ministry of Foreign Affairs, Royal Danish Ministry of Foreign Affairs, and Swedish International Development Cooperation Agency.

Thank you to the many contributors, reviewers, editors, and designers who shared their time, insights, and creativity. Contributors: Nadine LombardoHan, Tishara Rajagopal. Paper Reviewers: Harsha Meenawat, Eric Mackres, Aditya Chunekar, Hari Natarajan, Clay Nesser, Crystal Hall, Sahana Goswami, Shahana Chattaraj. Production: Romain Warnault, Caroline Taylor, and Billie Kanfer. Editor: Carlos Munoz Pina. We are also grateful to various VR project stakeholders and funders for supporting VR through funding, data support, implementation, and guidance. Utility Support: DSM BESCOM. Data and participation: Bangalore VR participants. Funding support and insights: University of Chicago

ABOUT THE AUTHORS

Mindy Hernandez is an applied behavioral scientist and the Lead of WRI's Living Lab for Equitable Climate Action.

Kiran Bhagavatula is senior manager, energy division, and leads the VR LITE program.

Santhosh Cibi is the head of energy at TIDE and leads the Vidyut Rakshaka program.

Ravichandran $\mathbf{K}$ is a consultant and mentor to the Vidyut Rakshaka program.

Sumathy Krishnan is the executive director at TIDE, handles strategic planning for the energy and environment group at TIDE, and conceptualizes programs for grassroots impact.

Sumedha Malaviya is a senior manager at the energy program in WRI India where she focuses on energy efficiency in buildings and urban energy transition

Bharath Jairaj is executive director at the energy program in WRI India where he leads the program's efforts to inform and catalyze India's transition to clean energy. 


\section{ABOUTTIDE}

Technology Informatics Design Endeavour (TIDE, www.tide-india.org) is a 28-year-old Bangalore based NGO, promoting sustainable development through innovative technological interventions. TIDE's work encompasses energy access and biomass-based cooking / industry solutions, Renewable Energy and Energy efficiency / conservation (RE \& EE), Environment Management, Technology based and innovative livelihoods for rural women. Since inception, we have developed / adapted and transferred technology options like improved cook stoves, biogas, biomass gasification, biomass briquetting and energy audits. Our work aligns with Sustainable Development Goals (SDGs) of UN, primarily 3,5,7,11,12 and 13.

\section{ABOUT WR}

World Resources Institute is a global research organization that turns big ideas into action at the nexus of environment, economic opportunity, and human well-being.

\section{Our Challenge}

Natural resources are at the foundation of economic opportunity and human well-being. But today, we are depleting Earth's resources at rates that are not sustainable, endangering economies and people's lives. People depend on clean water, fertile land, healthy forests, and a stable climate. Livable cities and clean energy are essential for a sustainable planet. We must address these urgent, global challenges this decade.

\section{Our Vision}

We envision an equitable and prosperous planet driven by the wise management of natural resources. We aspire to create a world where the actions of government, business, and communities combine to eliminate poverty and sustain the natural environment for all people.

\section{Our Approach}

COUNT IT

We start with data. We conduct independent research and draw on the latest technology to develop new insights and recommendations. Our rigorous analysis identifies risks, unveils opportunities, and informs smart strategies. We focus our efforts on influential and emerging economies where the future of sustainability will be determined.

CHANGE IT

We use our research to influence government policies, business strategies, and civil society action. We test projects with communities, companies, and government agencies to build a strong evidence base. Then, we work with partners to deliver change on the ground that alleviates poverty and strengthens society. We hold ourselves accountable to ensure our outcomes will be bold and enduring.

SCALE IT

We don't think small. Once tested, we work with partners to adopt and expand our efforts regionally and globally. We engage with decision-makers to carry out our ideas and elevate our impact. We measure success through government and business actions that improve people's lives and sustain a healthy environment. 